\author{
Universidade de São Paulo \\ Escola Superior de Agricultura "Luiz De Queiroz"
}

Mapeamento pedológico digital via regressão geograficamente ponderada e lógica booleana: uma estratégia integrada entre dados espectrais terrestres e de satélite

\title{
Luiz Gonzaga Medeiros Neto
}

Dissertação apresentada para obtenção do título de Mestre em Ciências. Área de concentração: Solos e Nutrição de Plantas 


\title{
Luiz Gonzaga Medeiros Neto \\ Engenheiro Agrônomo
}

Mapeamento pedológico digital via regressão geograficamente ponderada e lógica booleana: uma estratégia integrada entre dados espectrais terrestres e de satélite versão revisada de acordo com a resolução CoPGr 6018 de 2011

\author{
Orientador: \\ Prof. Dr. JOSÉ ALEXANDRE MELO DEMATTÊ
}

Dissertação apresentada para obtenção do título de Mestre em Ciências. Área de concentração: Solos e Nutrição de Plantas

\section{Piracicaba}




\section{Dados Internacionais de Catalogação na Publicação DIVISÃO DE BIBLIOTECA - DIBD/ESALQ/USP}

\section{Medeiros Neto, Luiz Gonzaga}

Mapeamento pedológico digital via regressão geograficamente ponderada e lógica booleana: uma estratégia integrada entre dados espectrais terrestres e de satélite / Luiz Gonzaga Medeiros Neto. - - versão revisada de acordo com a resolução CoPGr 6018 de 2011. - - Piracicaba, 2017.

$$
53 \mathrm{p} .
$$

Dissertação (Mestrado) - - USP / Escola Superior de Agricultura "Luiz de Queiroz".

1. Mapeamento pedológico digital 2. Solo exposto 3. Regressão geograficamente ponderada 4. Lógica booleana L. . I. Título 
Dedico aos meus pais Gessé de Medeiros e Sônia Regina de Medeiros, a minha avó Wilma Campos de Medeiros e a minha amada Renata Garofalo Silveira 


\section{AGRADECIMENTOS}

À Deus.

À minha família.

À Escola Superior de Agricultura "Luiz de Queiroz" (ESALQ) e ao Departamento de Ciência do Solos pela oportunidade concedida.

Ao meu orientador Prof.. Dr. José Alexandre Melo Demattê, pela oportunidade, confiança, incentivo e dedicação dada.

Aos integrantes Geocis pelo apoio e amizade, Arnaldo Barros, Bruna Gallo, Caio Fongaro, Clécia Cristina, Danilo Romero, João Brasiliano, José Lucas, Karina Prazeres, Luis Bedin, Marcos Sato e Veridiana Sayão.

À Raízen pela base de dados de dados de solos da Usina Santa Helena.

À Agrofficio, na pessoa do Luiz Eduardo Oliveira de Faria, pelo apoio e incentivo.

À família da república HK sempre merecedores de agradecimentos. 
Ora, a fé é o firme fundamento das coisas que se esperam, e a prova das coisas que se não veem.

Hebreus 11:1 


\section{SUMÁRIO}

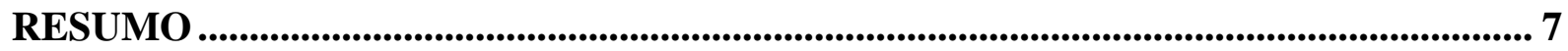

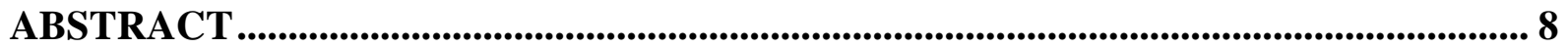

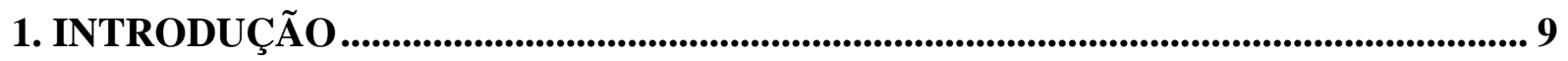

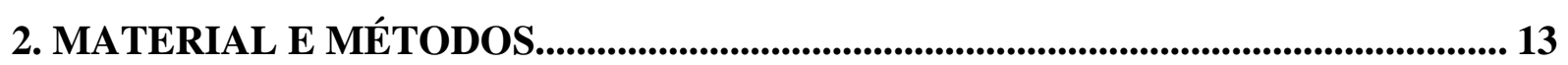

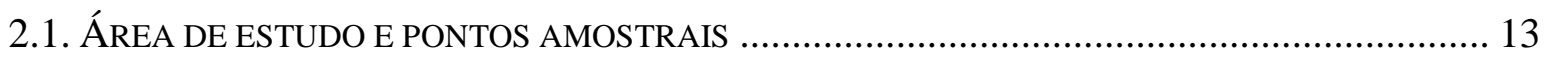

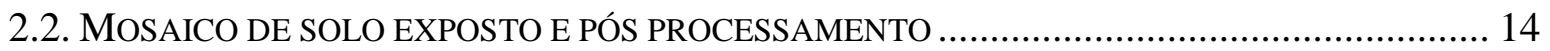

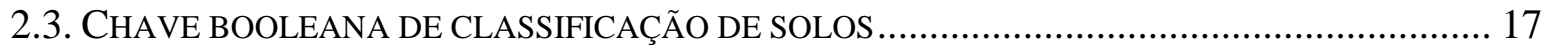

2.4. ANÁLISE MULTIVARIADA PARA ESPACIALIZAÇÃO DE ATRIBUTOS DO SOLO ..................... 19

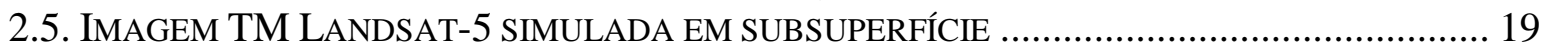

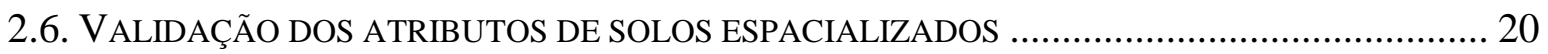

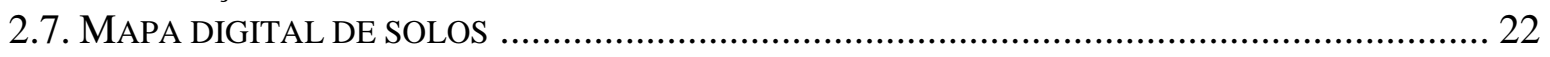

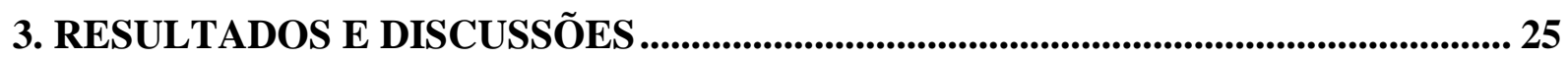

3.1. ESPACIALIZAÇ̃̃O DOS ESPECTROS DAS BANDAS TM LANDSAT-5 SIMULADAS EM

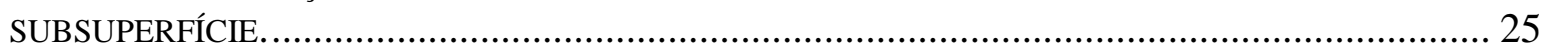

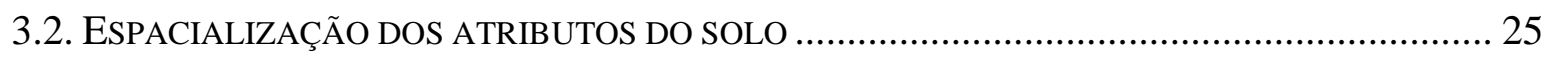

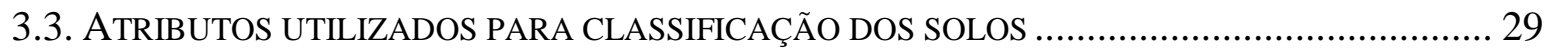

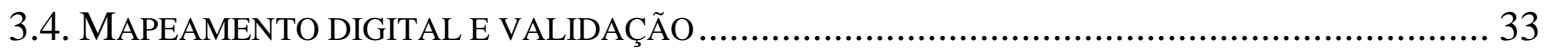

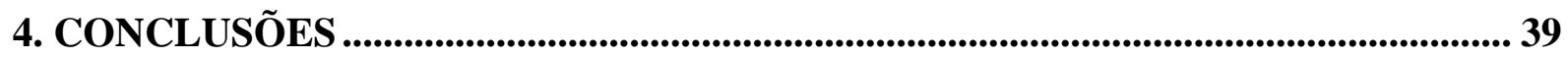

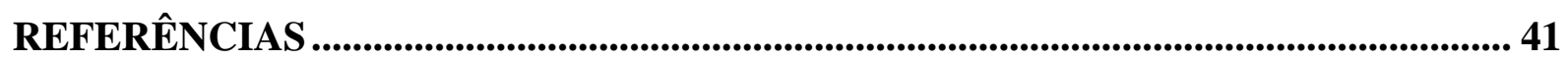

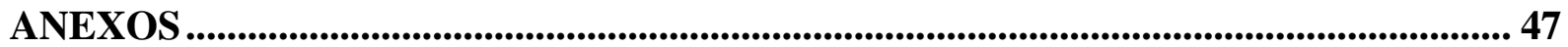




\section{RESUMO}

\section{Mapeamento pedológico digital via regressão geograficamente ponderada e lógica}

\section{booleana: uma estratégia integrada entre dados espectrais terrestres e de satélite}

Mapas pedológicos são importantes fontes de informação necessárias à agricultura, mas praticamente inexistentes em escalas adequadas para o Brasil, e seu levantamento pelo método convencional para a demanda brasileira é inviável. Como alternativa ao problema, mapeamento pedológico digital apresenta-se como uma área do conhecimento que envolve as relações das informações de campo, laboratório e pontuais de solos com métodos quantitativos via imagens de satélite e atributos do relevo para inferir atributos e classes. A literatura destaca, portanto, a importância do estudo da posição espacial de pontos amostrais na estimativa de atributos do solo a partir dos valores espectrais de imagens de satélite, aliado a isso, faz-se importante o cruzamento dos atributos do solo estimados e espacializados para chegar a classes de solo. Face ao exposto, o objetiva-se o desenvolvimento de uma técnica via imagem de satélite, dados espectrais e atributos do relevo, integrados por lógica booleana, para determinar mapas pedológicos. O trabalho foi realizado no município de Rio das Pedras, SP e entornos, numa área total de 47.882 ha. Onde, realizou-se processamento de imagens de satélites multitemporais, para obtenção da informação espectral da superfície de solo exposto. Esta informação foi correlacionada com espectro de laboratório de pontos amostrais em subsuperfície (profundidade $80-100 \mathrm{~cm}$ ) e estimou-se os espectros simulando bandas de satélite para locais desconhecidos. Elaborou-se uma chave de classificação de solos por cruzamento de mapas de atributos via lógica booleana, onde definiu os seguintes atributos a serem mapeados: argila, V\% e matéria orgânica (M.O) na profundidade 0-20 cm e argila, CTC, V\%, m\%, Al, ferro total, matiz, valor e croma na profundidade $80-100 \mathrm{~cm}$. As estimativas de espectros em subsuperfície e dos atributos dos solos nas duas profundidades foram realizadas pela técnica multivariada regressão geograficamente ponderada (GWR), que teve seu desempenho preditivo avaliado pela comparação com desempenho preditivo da técnica de regressão linear múltipla (MRL). Os resultados mostraram correlação entre os espectros das duas profundidades, com $\mathrm{R}^{2}$ de validação acima 0.6. Argila (0-20 e 80-100 cm), matiz, valor e croma foram os atributos do solo que obtiveram as melhores estimativas com $\mathrm{R}^{2}$ acima 0.6. A técnica multivariada GWR obteve-se desempenho superior ao MRL. O mapa pedológico digital comparado aos mapas de solos detalhados de levantamentos convencionais obteve índice kappa de $34.65 \%$ e acurácia global de $54,46 \%$. Tal resultado representa um nível regular de classificação. Por outro lado, deve se considerar que se trata de uma região de alta complexidade geológica e compreendendo heterogeneidade de solos. A técnica desenvolvida mostra-se com potencial de evolução no mapeamento digital de solos à medida que forem evoluindo as estimativas de atributos de solos e ajustes nos critérios da chave de classificação.

Palavras-chave: 1. Mapeamento pedológico digital 2. Solo exposto 3. Regressão geograficamente ponderada 4. Lógica booleana 


\section{ABSTRACT \\ Digital pedological mapping by geographically weighted regression and boolean logic: an integrated strategy between terrestrial and satellite spectral data}

Soil maps are important sources of information necessary for agriculture, but practically absent in appropriate scales for Brazil, and its mapping by the conventional method for the brazilian demand is impracticable. How an alternative to the problem, digital pedological mapping appears as an area of knowledge that involves the relationship of field information, laboratory and point of soils with quantitative methods by satellite images and relief attributes to predict attributes and classes. The literature highlights therefore the importance of studying the spatial position of sampling points in the estimation of soil attributes from spectral values of satellite images, combined to this, is an important the crossing of the estimated and spatialized soil attributes to get the soil classes. In view of exposed, the objective is the development of a technique satellite image, spectral data and attributes of relief, integrated by boolean logic to determine soil maps. The work was carried out in Rio das Pedras county, SP, and surroundings, in a total area of 47,882 ha. Which was held processing multitemporal satellite images, to obtain spectral information of exposed soil surface. This information was correlated with laboratory spectra of sample points in the subsurface (depth $80-100 \mathrm{~cm}$ ) and was estimated spectra simulating satellite bands to unknown locations. Produced is a soil classification key for cross attribute maps by boolean logic, which defines the following attributes to be mapped: clay, cation saturation and organic matter $(\mathrm{OM})$ in the $0-20 \mathrm{~cm}$ depth and clay, CEC, cation saturation, aluminiu saturation, Al, total iron, hue, value and chroma in depth $80-100 \mathrm{~cm}$. The estimates spectra subsurface and soil attributes in two depths were performed by multivariate technique geographically weighted regression (GWR), which had its predictive performance is evaluated by comparison with predictive performance of multiple linear regression (MRL). The results showed a correlation between the spectra of the two depths, with validation $\mathrm{R}^{2}$ above 0.6 . Clay (0-20 and 80-100 $\mathrm{cm}$ ), hue, value and chroma were the soil attributes obtained the best estimates $\mathrm{R}^{2}$ above 0.6. The GWR multivariate technique yielded better performance than MRL. The digital soil map compared to the detailed soil maps of conventional surveys obtained kappa index of $34.65 \%$ and overall accuracy of $54.46 \%$. This result is a regular level of classification. On the other hand, it must be considered that it is a highly complex geological region and comprising heterogeneity of soils. The technique developed shows with potential developments in digital soil mapping as they evolve estimates of soil attributes and adjustments to the classification key criteria.

Keywords: 1. Digital pedological mapping 2. Soil exposed 3. Geographically weighted regression 4 . Boolean logic 


\section{INTRODUÇÃO}

Mapas de solos são fontes importantes de informações, geograficamente distribuídas, utilizadas para diversos fins, sendo recomendado mapas de solos em escalas pequenas (1:750.000 ou 1:1.000.000) apenas para trabalhos regionais, devendo-se utilizar mapas de grandes escalas (até 1:50.000) para trabalhos que envolvem áreas do tamanho de uma propriedade agrícola (Dalmolin et al., 2004).

No Brasil, a maior disponibilidade de mapas de solos está relacionada aos levantamentos pedológicos oriundos do Projeto Radam Brasil, que correspondem a 80\% território brasileiro mapeado em escala de 1:1.000.000 (Figueiredo et al., 2008). A disponibilidade de mapas em grandes escalas é insatisfatória, existindo apenas $0.25 \%$ do território coberto por levantamentos detalhados (escalas $\geq 1: 20.000$ ) ou semidetalhados (escalas de 1:20.000 a 1:100.000), e apenas 17,1\% com levantamentos de reconhecimento (escalas entre 1:100.000 e 1:750.000). (Mendonça-Santos e Santos, 2007).

Fica evidente a necessidade de levantamentos pedológicos em grandes escalas, que se forem feitos pelo método tradicional, apresentam os problemas de altos custos, altas demandas de tempo, exigem pedólogos experientes e necessitam de muitas visitas ao campo (Figueiredo et al., 2008; Neumann, 2012). Tais problemas podem ser amenizados por meio do Mapeamento Digital de Solo (MDS).

O MDS trata-se de uma área do conhecimento que envolve a relação das informações de campo, laboratório e pontuais de solos com métodos quantitativos para inferir sobre os padrões espaciais dos solos em várias escalas temporais e espaciais (Grunwald, 2010). Várias são as estratégias adotadas nos estudos dessas relações, que podem ter abordagens preditivas de atributos ou de classes de solos. Nessas estratégias, estimam-se teores de atributos ou classes de solos em locais desconhecidos a partir amostras conhecidas que têm correlação com dados espectrais de satélite e/ou dados de relevo, via técnicas multivariadas, e assim obter mapas com classes ou atributos do solo. Observa-se que os trabalhos realizados nos estudos de predição se dividem entre estimativas de atributos (Moore et al., 1993; Odeh et al., 2006; Junior et al., 2008; Dematte et al., 2009; Mulder et al., 2011; Gerighausen et al., 2012; Genú et al., 2013; Franceschini et al., 2015) e estimativa de classes de solos (Demattê et al., 2004, 2016; Ziadat, 2007; Figueiredo et al., 2008; ten Caten et al., 2013, 2009; Genú e Demattê, 2012; Arruda et al., 2013; Giasson et al., 2013; Adhikari et al., 2014; Fiorio et al., 2014; Teske et al., 2015; Dias et al., 2015) via imagens de satélite e/ou dados de relevo. 
Além das estratégias de predição via imagens de satélite e/ou dados de relevo, também se apresenta como importante ferramenta, a biblioteca espectral. Caracteriza-se por um banco de dados de amostras de terra e respectivas análises laboratoriais e espectrais. De posse de uma amostra de terra desconhecida, obtém-se o espectro, e através deste a estimativa de um atributo a partir de modelos de predição calibrados via biblioteca. Tal metodologia vem sendo utilizada com sucesso por vários pesquisadores (Shepherd e Walsh, 2002; He, 2006; Rossel, 2007, 2008; Ben-Dor et al., 2008; Fiorio e Demattê, 2009; Rossel et al., 2010; Araújo et al., 2014; Khayamim et al., 2015; Nocita et al., 2015)

Nas estimativas de atributos do solo o método mais empregado é a Regressão Linear Múltipla (MLR), que correlaciona um dado atributo com múltiplas variáveis independentes, que pode ser as bandas de imagens de satélite, e/ou atributos do relevo como o observado em trabalhos similares aos desenvolvidos por Fiorio et al. (2003) e Odeh et al. (2006). O MRL pode ser representado pela equação 1 :

$$
y_{i}=a_{0}+\sum_{k} a_{k} x_{i k}+\varepsilon_{i}
$$

sendo, $y_{i}$ representa o atributo predito no ponto $i, a_{k}$ representa coeficiente multiplicador à variável independente $x_{i k}$, e $\varepsilon_{i}$ é o erro da estimativa de predição no ponto $i$ (Fotheringham et al., 1998).

A maior parte dos estudos com predição pelo método MRL, não consideram a posição geográfica do ponto amostral nas estimativas de um dado atributo do solo. Neste caso, a Regressão Geograficamente Ponderada (GWR) apresenta-se como alternativa, já que considera a posição geográfica das amostras, determinando pesos ponderados, que são considerados nas estimativas dos atributos (Fotheringham et al., 1998). Basicamente a equação do GWR é uma extensão da equação 1, acrescentada da informação da posição geográfica e sendo representado pela equação 2 :

$$
y_{i}=a_{0}+\sum_{k} a_{k}\left(u_{i}, v_{i}\right) x_{i k}+\varepsilon_{i}
$$

sendo, $\left(u_{i}, v_{i}\right)$ representantes das coordenadas do ponto $i$ no espaço, $a_{k}\left(u_{i}, v_{i}\right)$ é o peso geograficamente ponderado da função continua $a_{k}(u, v)$ do ponto $i, x_{i k}$ representa a variável independente $k$ do ponto $i$ e $\varepsilon_{i}$ é o erro da estimativa de predição no ponto $i$ (Fotheringham et al., 1998).

A literatura destaca, portanto, a importância do estudo da posição espacial de pontos amostrais na estimativa de atributos do solo a partir dos valores espectrais de imagens de satélite, aliado ai isso, faz-se importante o cruzamento dos atributos do solo estimados e 
espacializados para chegar a classes de solo. Com isso, espera-se que características específicas de classes pedológicas obtidas via geoprocessamento e pedotransferência possam ser sobrepostas gerando um mapa compatível com o que ocorre no campo. Face ao exposto, o objetiva-se o desenvolvimento de uma técnica via imagem de satélite, dados espectrais e atributos do relevo, integrados por lógica booleana, para determinar mapas pedológicos. 


\section{MATERIAL E MÉTODOS}

\section{1. Área de estudo e pontos amostrais}

A área de estudo está situada em uma região representada por um quadrante que abrange o entorno do município de Rio das Pedras, estado São Paulo, Brasil, correspondendo a uma área total de 47.882 ha, onde se encontra uma variação de entre 500 e 700 m (Figura 1). Nesse local, foram utilizadas amostras de solos nas profundidades de 0-20 e 80-100 cm coletadas em 328 pontos georreferenciados, provenientes do banco de dados do Laboratório de Sensoriamento Remodo do Departamento de Ciências do Solo, da Escola Superior de Agricultura "Luiz de Queiroz" - Esalq/USP. Estas amostras foram analisadas em laboratórios convencionas para obtenção dos valores dos atributos químicos segundo Raij; Andrade \& Cantarella Quaggio (2001) e granulométricos segundo Camargo et al. (1986). Além das análises convencionais, foram lidos os valores de reflectância, por meio do sensor de laboratório FIELDSPEC PRO, segundo metodologia descrita por Terra; Demattê \& Viscarra Rossel (2015).

A geologia da região se mostra complexa, segundo folha geológica de Piracicaba SF 23 - M 300, escala de publicação 1:100.000 (MEZZALIRA, 1966), sendo observas as seguintes classes: Ct - Período Carbonífero, formação Grupo Tubarão, constituído por arenitos, siltitos, varvitos, tilitos e conglomerados; Jbp - Período Jurássico, formação Botucatu Pirambóia, constituído por arenito, siltitos e folhelhos; Ksg - Período Cretáceo, formação Serra Geral, constituído por basalto, arenito, inter-trap e diábasio; Pc. Período Permiano, formação Grupo Estrada Nova Formação Corumbataí, constituído por siltitos, folhelhos, calcários e sílex; e Pi - Período Permiano, formação Grupo Estrada Nova Formação Irati, constituído por folhelhos, pirobetuminosos, dolomitos, siltitos. Sílex (Figura $1)$. 


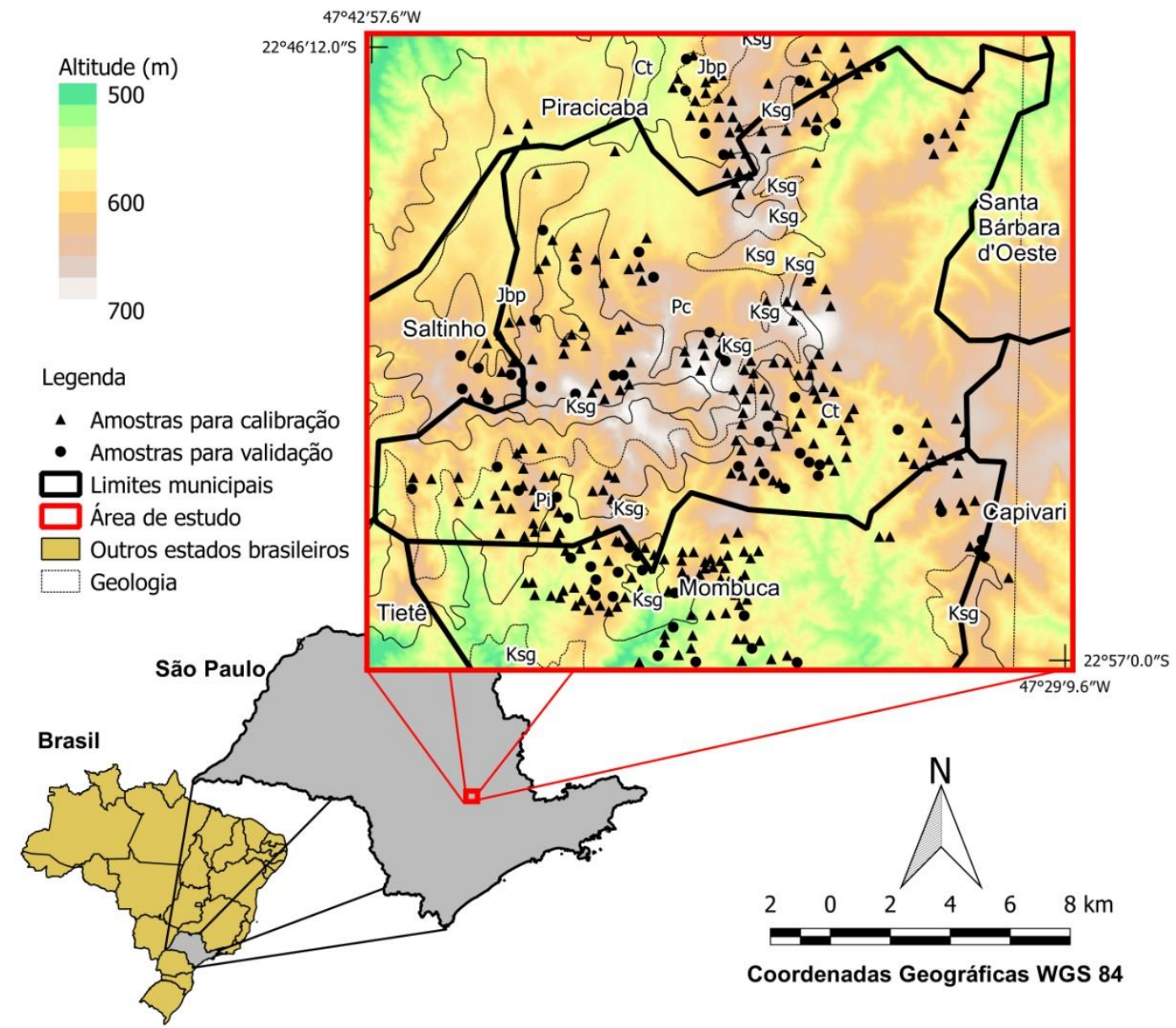

Figura 1. Localização da área de estudo, distribuição dos pontos amostrais e geologia da região sobrepostos a um modelo digital de elevação (SRTM). Ct - Período Carbonífero, formação Grupo Tubarão; Jbp - Período Jurássico, formação Botucatu Pirambóia; Ksg - Período Cretáceo, formação Serra Geral; Pc. Período Permiano, formação Grupo Estrada Nova Formação Corumbataí; e Pi - Período Permiano, formação Grupo Estrada Nova Formação Irati (MEZZALIRA, 1966).

\subsection{Mosaico de solo exposto e pós processamento}

Foi utilizada base de dados espectrais de solo exposto obtidos de imagens de satélite landsat-5, elaborada no Laboratório de Sensoriamento Remodo do Departamento de Ciências do Solo, da Escola Superior de Agricultura “Luiz de Queiroz” - Esalq/USP, por Gallo (2015), segundo metodologia para detecção de solo exposto desenvolvida por Fongaro (2015). As imagens landsat-5 que deram origem a essa base de dados estão localizadas na cena de orbita 220 e ponto 76, das datas 20/09/1994, 24/08/1996, 11/08/1997, 29/07/1998, 02/09/1999, 16/06/2000, 24/07/2002, 14/08/2004, 16/07/2005, 19/07/2006, 20/06/2007, 28/08/2009 e 31/08/2010. Essas datas de imagem escolhidas foram as situadas nas épocas de maior ocorrências de solos expostos, devido as práticas preparo do solo por aração e gradadagem, referentes a renovação das áreas produtoras de cana-de-açucar. Tambem estão em épocas de menor ocorrência de nuvens e menor umidade do solo pela menor ocorrencia de chuvas 
(Gallo, 2015). Nessa metodologia de detecção de solo exposto ocorrem as seguintes etapas: (1) correção atmosférica e conversão das informações dos pixels das imagens de numero digital em dados de reflectância; (2) geração de índices de vegetação e outros índices entre bandas das imagens de satélite; (3) definição de limites de valores entre solo exposto e o restantes das coberturas do solo; (4) extração apenas das informações de solo exposto das imagens em cada uma de suas datas; (5) junção das imagens de solo exposto em uma única imagem, formando um mosaico de solo exposto, em que foram escolhidos os pixels mais secos nos locais em que houve sobreposição de imagens (Fongaro, 2015).

Em relação a etapa da junção das imagens de solo exposto, para este trabalho, realizou-se uma adaptação em relação a proposta por Fongaro (2015). Neste caso, ao invés de utilizar o pixel mais seco nos locais de sobreposição das imagens, realizou-se a média dos pixels para os locais onde houve sobreposição. Antes dessa média, realizaram-se pósprocessamentos em cada uma das imagens de solo exposto dos vários períodos, onde se aplicou um filtro raster para fechamento de pequenas lacunas, que representam ausência de informações na imagem de solos exposto, e com isso, visou-se aumentar as áreas de solo exposto em cada uma dessas imagens (Figura 2). Neste pós-processamento, foi utilizada a ferramenta Close Gaps do Software SAGA GIS versão 2.1.2.

Após a etapa de fechamento de lacunas, juntaram-se as imagens dos vários períodos em uma única imagem de solo exposto, que neste trabalho é denominada de Mosaico de Solo Exposto (MSE). Como supracitado esse MSE foi gerado pela média entre os pixels sobrepostos das imagens dos diferentes períodos. A ação conjunta do fechamento de lacunas e da média entre os pixels objetivou eliminar ruídos e transições abruptas nos valores de refletância, que são possíveis de se observar, por exemplo, em uma composição colorida R:5, $\mathrm{G}: 4, \mathrm{~B}: 3$ do MSE.

O MSE gerado ainda apresentou vazios de informação, estes em grandes áreas e que não são viáveis de serem preenchidos através da ferramenta Close Gaps. Isso por ocorrer vários fatores, como locais com coberturas vegetais constantes ao longo dos vários períodos (áreas de restrição ambiental, florestas plantadas, etc), áreas de solo exposto que não foram detectadas nas imagens escolhidas, presença de nuvens, presença de palhada, entre outros. Assim, utilizou-se a geoestatística para preencher esses vazios de informação (Figura 02). Pela geoestatística, espacializou-se os valores de reflectância extraídos das bandas do MSE em uma grade amostral de 200 por $200 \mathrm{~m}$, gerando assim o denominado no presente trabalho de Mosaico de Solo Exposto Krigado (MSEKG). Esse MSEKG foi validado comparando-o com os valores de reflectância extraídos do MSE para uma grade de 100 por 100 m por meio 
de coeficientes de determinação $\left(\mathrm{R}^{2}\right)$. A ferramenta utilizada para a krigagem foi a Spatial and Geostatistics do Software SAGA GIS versão 2.1.2.

Após a geração do MSEKG, realizou-se a sobreposição do MSE ao MSEKG, tendo assim preenchidos todos os vazios de informação de solo exposto do MSE pela informações espectrais do MSEKG, gerando-se assim, o denominado no presente trabalho de MSE unido ao MSEKG (MSEKGU) (Figura 2).

O Anexo A apresenta os resultados relacionados ao pós processamento das imagens de solo exposto.

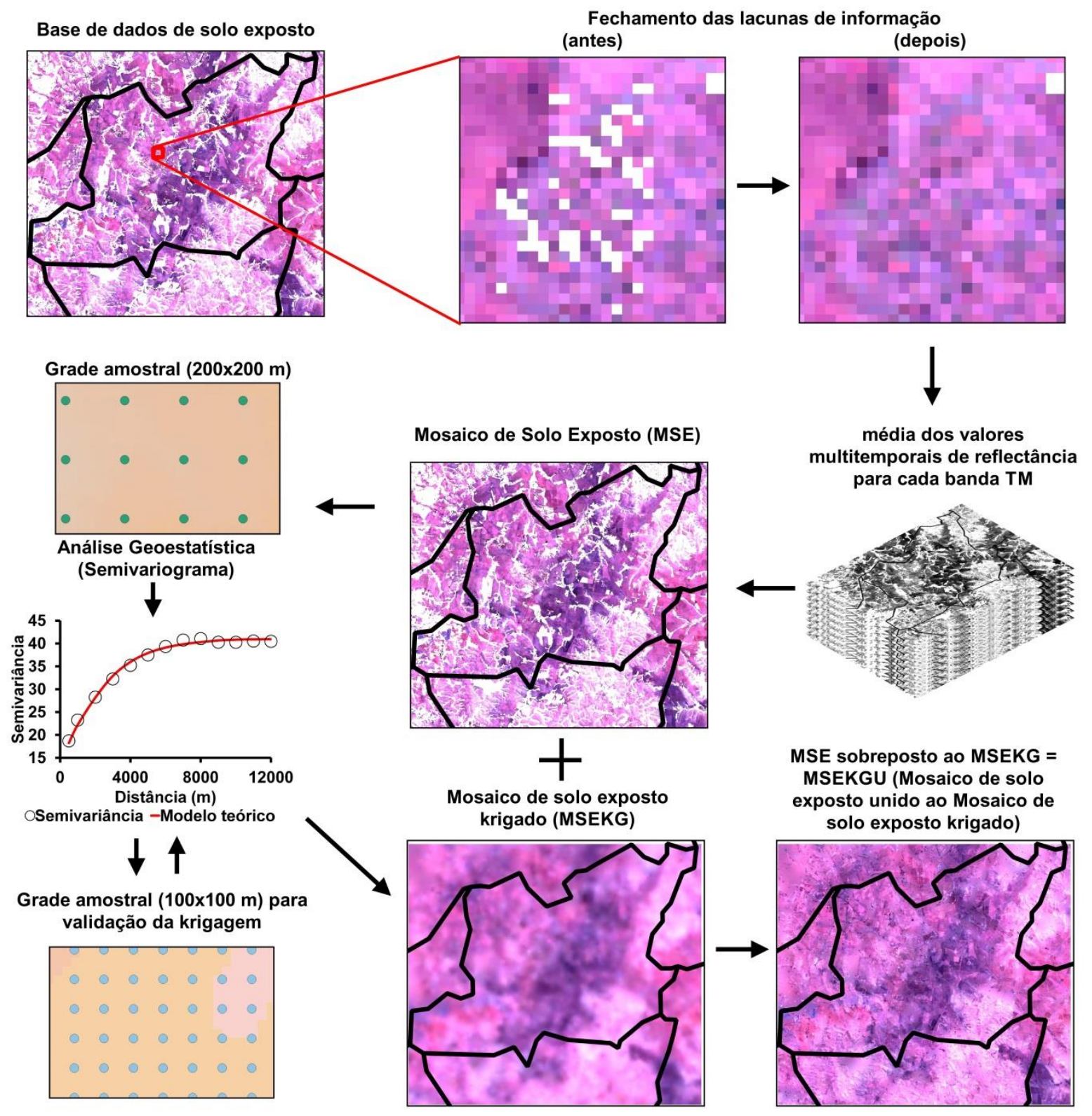

Figura 2. Sequência de etapas do pós-processamento da imagem de solo exposto. 


\subsection{Chave booleana de classificação de solos}

A partir de estudo do Sistema Brasileiro de Classificação de Solos (EMBRAPA Solos, 2014), da análise da qualidade dos atributos do solo espacializados, e da análise das relações desses atributos do solo e do relevo com os solos da região, elaborou-se uma chave booleana de classificação de solos até o quarto nível categórico. Segundo Moreira (2001), um modelo booleano envolve a combinação lógica de camadas através de operadores condicionais, em que cada camada utilizada pode ser entendida como um plano de informação, que em conjunto são combinados segundo uma sequencia lógica para dar suporte a uma hipótese ou proposição definida. A Figura 3 apresenta de forma simplificada parte da chave booleana elaborada, onde exemplifica a separação de solos com e sem horizonte diagnóstico B textural, por meio de um fluxograma (Figura3a) e de um script de acordo com a linguagem da ferramenta GeoFormula do software TNTMips (Microimages) versão 2008:74 (Figura 3b).

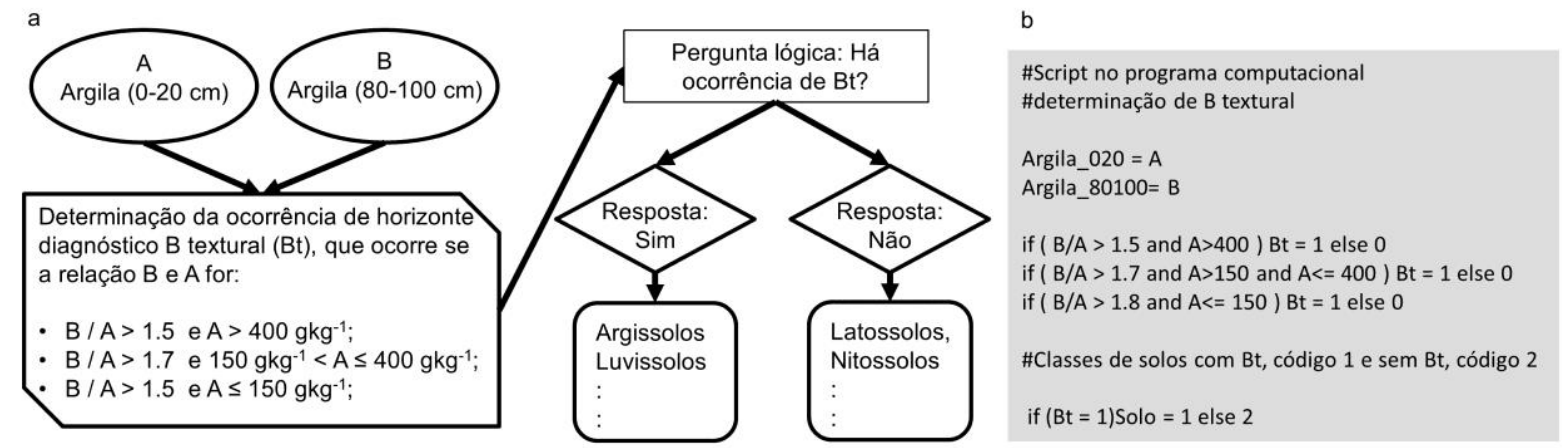

Figura 3. Chave de classificação de solos por regras booleana simplificada, exemplificando a separação entre classes de solos com e sem horizonte diagnóstico Bt, na forma de fluxograma (a) e na forma de script elaborado na ferramenta Geoformula do software TNTMips (b).

As informações combinadas de acordo com as sequências lógicas definida na chave booleana foram:

i. Cor do solo Carta de Munsel: representada pelos atributos Matiz, Valor e Croma, na profundidade de 80 a $100 \mathrm{~cm}$, e define o segundo nível categórico para os Latossolos, Nitossolos e Argissolos. O atributo matiz foi transformado em valor numérico, sendo $\mathrm{R}=0, \mathrm{YR}=10$ e $\mathrm{Y}=20$. Assim, acrescenta-se o valor do intervalo da matiz a um dos valores 0, 10 ou 20 e então obtém a matiz em valor numérico. A definição dos limites dos valores de cores, seguiu o Sistema Brasileiro de Classificação de Solos (EMBRAPA Solos, 2014), como exemplificado a seguir:

i. Argissolos Amarelos: Matiz maior ou igual a 7.5YR (17.5); 
ii. Latossolos Vermelho Amarelos: quando não atender a nenhum dos critérios anteriores para coloração de Argissolos;

iii. Latossolos ou Nitossolos Vermelhos: Matiz menor ou igual 2.5YR (12.5)

i. Textura: definida pelos teores de argila nas camadas superficiais $(0-20 \mathrm{~cm})$ e subsuperficiais $(80-100 \mathrm{~cm})$. Este atributo é importante para delimitação do horizonte B textural, Neossolos Quartzarênicos, separação de 'Nitossolos e Latossolos de Argissolos, caráter psamítico e argilas de atividade alta (Ta) e baixa (Tb) (Embrapa, 2014). Também por meio de classes de argila na camada subsuperficial separou-se as classes de solo, onde as classes texturais foram: muito arenosa $\left(<100 \mathrm{gkg}^{-1}\right)$, arenosa $\left(100-150 \mathrm{gkg}^{-1}\right)$, médio arenosa (150-250 $\left.\mathrm{gkg}^{-1}\right)$, médio argilosa (250-350 $\left.\mathrm{gkg}^{-1}\right)$, argilosa (350-650 $\left.\mathrm{gkg}^{-1}\right)$ e muito argilosa (>650 $\left.\mathrm{gkg}^{-1}\right)$ (DEMATTÊ e DEMATTÊ, 2009).

ii. Matéria Orgânica (M.O.): a matéria orgânica superficial $(0-20 \mathrm{~cm})$ é importante para delimitação de Organossolos (M.O>13\%) e horizonte diagnóstico A Chernozêmico (Carbono orgânico > $6 \mathrm{gkg}^{-1}$, aliado a V\%>65) (EMBRAPA Solos, 2014).

iii. Capacidade de Trocas Catiônicas (CTC): esse atributo em subsuperfície $(80-100 \mathrm{~cm})$ é importante para definição da atividade das argilas, calculada pela equação 3:

$$
\frac{1000 \times C T C}{\text { Teor de Argila }}
$$

(Equação 3)

sendo, CTC é dado em cmolc $\mathrm{kg}^{-1}$ e Teor de Argila é dado em $\mathrm{gkg}^{-1}$, e será de atividade alta (Ta) se o valor for maior ou igual a 27 cmolc kg-1 argila, se não será de atividade baixa (Tb) (EMBRAPA Solos, 2014).

iv. Saturação por Bases (V\%): importante para delimitação de áreas com caráter eutrófico $(\mathrm{V} \% \geq 50)$ ou distróficos $(\mathrm{V} \%<50)$, para delimitação do horizonte diagnóstico A Chernozêmico (V\%>65, aliado Carbono orgânico $>6 \mathrm{gkg}^{-1}$ ), e para o calculo do caráter alítico ( $\mathrm{Al} \geq 4 \mathrm{cmolc} \mathrm{kg}^{-1}, \mathrm{CTC} / \mathrm{Teor}$ de argila $\geq 20 \mathrm{cmolc} \mathrm{kg}^{-1}, \mathrm{~m} \% \geq 50$ ou $\left.\mathrm{V} \%<50\right)$ sendo calculado segundo a equação 4 :

$$
V \%=\frac{100 \times S B}{C T C}
$$

sendo, SB e CTC são dados em cmolc kg-1 (EMBRAPA Solos, 2014).

v. Ferro Total $\left(\mathbf{F e}_{2} \mathbf{O}_{3}\right)$ : importante para delimitação do caráter férrico $\left(\mathrm{Fe}_{2} \mathrm{O}_{3} \geq 180 \mathrm{~g} \mathrm{~kg}^{-1}\right)$ (EMBRAPA Solos, 2014);

vi. Saturação por Alumínio (m\%): importante para delimitação de áreas com caráter alítico ( $\mathrm{Al} \geq 4$ cmolc kg${ }^{-1}, \mathrm{CTC} /$ Teor de argila $\geq 20$ cmolc kg ${ }^{-1}, \mathrm{~m} \% \geq 50$ ou V\%<50) necessárias para delimitação de Nitossolos (EMBRAPA Solos, 2014). A equação 5 apresenta o calculo do $\mathrm{m} \%$ : 


$$
m \%=\frac{100 \times A l}{S B+A l}
$$

sendo, SB e Al são dados em cmolc kg-1 (EMBRAPA Solos, 2014)

vii. Alumínio (Al): importante para delimitação de áreas com caráter alítico ( $\mathrm{Al} \geq 4 \mathrm{cmolc} \mathrm{kg}^{-1}$, CTC/Teor de argila $\geq 20$ cmolc $\mathrm{kg}^{-1}, \mathrm{~m} \% \geq 50$ ou V\%<50), necessárias para delimitação de Nitossolos (EMBRAPA Solos, 2014).

viii.Declividade: atributo do relevo importante para separar Cambissolos e Neossolos Litólicos das demais classes de solo (maiores declividades), e Nitossolos de Latossolos, os limites observados em mapeamento existente, para a região é declividade entre 4.5 e $9 \%$ para separar Nitossolos de Latossolos, entre 9 e 20\% para separar Cambissolos + Neossolos Litólicos dos demais solos, e acima de 20\% para apenas Neossolos Litólicos.

ix. Altitude Normalizada: atributo do relevo que redimensiona a relação entre as aguadas e as redes de drenagem em valores percentuais, assim, 100\% representa as partes mais altas de uma bacia e $0 \%$ representa os canais de drenagem, neste atributo, observou que o valor de $35 \%$ mapeia com bastante precisão os canais de drenagem, que associados a declividade plana, pode mapear a associação de Neossolos Flúvicos com Gleissolos.

\subsection{Análise multivariada para espacialização de atributos do solo}

Nas análises multivariadas, os pontos amostrais foram separados aleatoriamente em amostras para calibração das predições de atributos de solo (80\%) e amostras para validação dessas predições (20\%) (Figura 1). Essa separação foi realizada por ferramenta de seleção aleatória do software Quantum GIS 2.14.9.

Após a separação aleatória, os atributos do solo definidos na chave de classificação booleana, foram espacializados por meio de regressões multivariadas, correlacionando as amostras de calibração (profundidade de 0-20 ou 80-100 cm) com atributos do relevo e as reflectâncias das bandas TM dos mosaicos de solo exposto MSEKG e MSEKGU. Os processamentos para as análises multivarias GWR e MLR foram realizados no pacote Spatial and Geostatistics do software SAGA GIS versão 2.1.2.

\subsection{Imagem TM Landsat-5 simulada em subsuperfície}

Nos pontos amostrais, simularam-se os valores de reflectância das bandas TM Landsat-5 para a profundidade de $80-100 \mathrm{~cm}$, a partir das reflectância obtidas via FIELDSPEC. Essa simulação de bandas de imagem de satélite é pratica comum na área de sensoriamento remoto (Nanni e Demattê, 2006). Os TM simulados nos pontos calibração 
foram espacializados por GWR e MRL, sendo utilizados dos dados de reflectância de superfícies dos mosaicos MSEKG ou MSEKGU. Assim, obtiveram imagens das bandas TM simuladas em subsuperfície, que foram utilizadas/testadas como variáveis independentes para predições dos atributos na profundidade de 80-100 cm. Essas imagens TM simuladas em subsuperfície foram denominadas como: Mosaico de solo exposto simulado em subsuperfície a partir do MSEKG (MSEKG2); Mosaico de solo exposto simulado em subsuperfície a partir do MSEKGU (MSEKGU2).

A Figura 4a apresenta as etapas de predição de atributos do solo nas profundidades de 0-20 e 80-100 cm até geração do mapa digital de solo via lógica booleana. De acordo com o proposto, são estimados e espacializados os valores de reflectância em subsuperfície a partir de pontos amostrais com espectros obtidos via sensor de laboratório e correlacionados com os espectros de superfície presentes nas leituras de sensores orbitais. Esses espectros de subsuperfície serviram como variáveis independentes utilizadas para predição de atributos do solo na profundidade de $80-100 \mathrm{~cm}$. Na predição dos atributos nesta profundidade, também foram utilizados as reflectâncias obtidas via sensores orbitais, pois se acredita na correlação de espectros de superfície com atributos do solo em subsuperfície, assim como nas correlações de espectros superficiais e subsuperficiais. Assim, a figura 4b, ilustra pontualmente o que se espera obter dessas correlações, que possibilitam predizer em subsuperfície informações em áreas desconhecidas a partir de amostras conhecidas com informações espectrais de superfície.

A sequência ilustrativa da Figura 4a, apresenta a predição dos atributos do solo nas duas profundidades citadas, também foram testados/utilizados atributos do relevo associados às informações espectrais. Após a espacialização desses atributos, os mesmo foram sobrepostos em camadas e via lógica booleana a partir de parâmetros pré-definidos chegou-se as classes de solos.

\subsection{Validação dos atributos de solos espacializados}

As validações das predições dos atributos do solo e reflectância de subsuperfície foram do tipo externa, com os $20 \%$ dos pontos amostrais de validação (Figura 1) separados aleatoriamente e que não foram utilizados nas estimativas. No caso particular do atributo ferro $\left(\mathrm{Fe}_{2} \mathrm{O}_{3}\right)$, pela disponibilidade de poucos pontos analisados, a validação foi do tipo cruzada leave one out, que é uma validação interna, e foi utilizado apenas no método de predição MRL (Tropsha et al., 2003). 


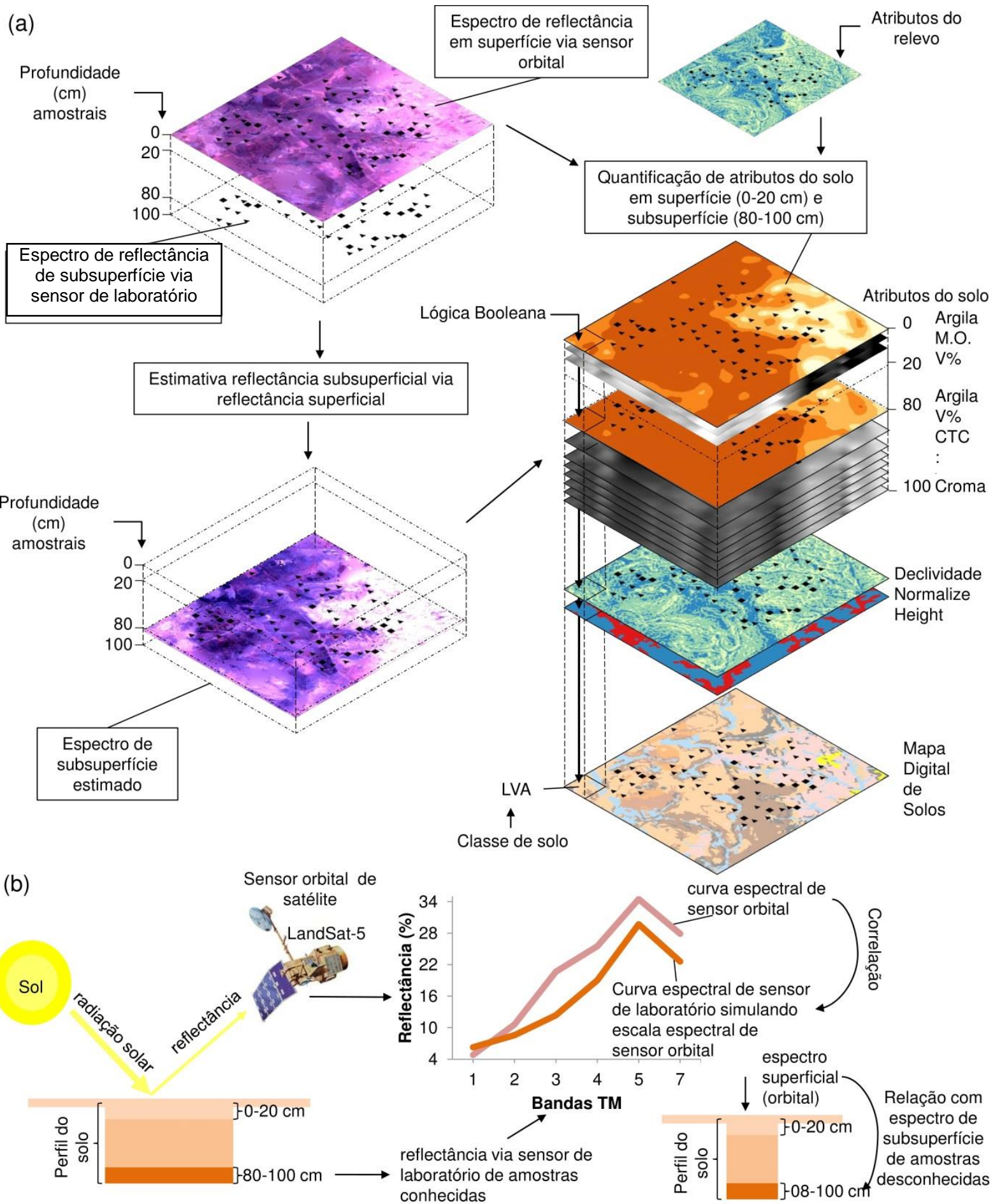

Figura 4. a. Etapas de predição de espectros de reflectância em subsuperfície, sequenciado por atributos do solo nas profundidades de 0-20 e 80-100 cm para geração de mapa digital de solos via lógica booleana; b. ilustração pontual das etapas do estudo das relação entre espectros de superfície via sensor de satélite e espectros de subsuperfície via sensor de laboratório. 
Não se utilizou o RPD, pois conforme demonstrado por Minasny \& Mcbratney (2013) o mesmo é redundante em relação ao $\mathrm{R}^{2}$, onde os autores recomendam o uso do RPIQ. Mesmo assim, utilizou-se as classes de interpretação do RPD para analisar os valores de RPIQ, que adaptado de Rossel (2007) são: muito ruim, RPIQ $\leq 1.5$; ruim, $1.5<\mathrm{RPIQ} \leq 2.0$; bom, 2.0<RPIQ $\leq 2.5$; e muito bom, RPIQ $>2.5$.

Para interpretação dos valores de $\mathrm{R}^{2}$, adotou-se as classes observadas em Terra; Demattê \& Rossel (2015), sendo estas: adequada, R² 0.75; bom, mas que pode ser melhorado, $0.5<\mathrm{R}^{2} \leq 0.75$; e não confiáveis para predição, $\mathrm{R} \leq 0.5$.

\subsection{Mapa digital de solos}

Os atributos de solo pré-definidos na elaboração da chave booleana e que apresentaram os melhores resultados segundo a etapa de validação, juntaram-se aos também predefinidos atributos de relevo e foram cruzados a partir dos critérios determinados na chave booleana, e assim gerou-se um mapa digital de classes de solos. Esta chave de classificação juntamente com os cruzamentos das informações espacializadas dos atributos foi realizada através da ferramenta GeoFormula do software TNTmips (MicroImages) versão 2008:74.

Para avaliar a qualidade do mapa digital de solos gerado, o mesmo foi comparado a levantamentos pedológicos existentes da região, elaborados nas escalas de 1:20.000 e $1: 100.000$.

O levantamento na escala de 1:20.000, é um levantamento pedológico semidetalhado de alta intensidade, proveniente do banco de dados do Laboratório de Sensoriamento Remoto Aplicado a Solos do Departamento de Ciência do Solo, Escola Superior de Agricultura "Luiz de Queiroz" - ESALQ/USP, e foi elaborado pelo método convencional de verificação de campo ao longo de topossequências e das correlações entre as variações de solo com as superfícies geomórficas (Santos et al., 1995). As classes até $2^{\mathrm{a}}$ ordem observadas neste levantamento foram: LATOSSOLOS VERMELHOS (LV); LATOSSOLOS VERMELHO AMARELOS (LVA); NITOSSOLOS VERMELHOS (NV); NITOSSOLOS HÁPLICOS (NX); ARGISSOLOS AMARELOS (PA), ARGISSOLOS BRUNO ACINZENTADOS (PBAC); ARGISSOLOS VERMELHO AMARELOS (PVA); ASSOCIAÇÕES NEOSSOLOS FLÚVICOS + GLEISSOLOS (NF+G); NEOSSOLOS REGOLÍTICOS (RR); ASSOCIAÇÃO NEOSSOLOS LITÓLICOS + CAMBISSOLOS (RL+C); PLANOSSOLOS (S); e LUVISSOLOS (T). O segundo nível categórico dos Latossolos, Argissolos e Nitossolos foi atualizados com os limites de cores no sistema munsell observados no atual Sistema Brasileiro de Classificação de Solos (EMBRAPA Solos, 2014). 
O levantamento de 1:100.000, é um levantamento pedológico semidetalhado de baixa intensidade, proveniente de trabalho elaborado pelo Instituto Agronômico de Campinas - IAC (Oliveira e Prado, 1989). As classes de solos presentes nesse levantamento foram atualizadas, para o sistema atual de classificação de solos (EMBRAPA Solos, 2014), sendo encontradas as seguintes classes: GLEISSOLOS (G); LATOSSOLOS VERMELHOS (LV); LATOSSOLOS VERMELHO AMARELOS (LVA); NITOSSOLOS VERMELHOS (NV); ARGISSOLOS VERMELHOS (PV); ARGISSOLOS VERMELHO AMARELOS (PVA); NEOSSOLOS LITÓLICOS (RL); LUVISSOLOS (T).

Para efeito comparativo, as classes de solos, dos levantamentos semidetalhados e do mapa digital foram simplificadas até as $1^{\mathrm{a}}$ e $2^{\mathrm{a}}$ ordens. Para as classes de solos, onde houve sobreposição entre esses mapas e que não foram detectadas por um dos mapeamentos, as mesmas foram associadas à outra classe que possa ter mais semelhança. Como citado anteriormente, o mapa referência apresentou algumas associações envolvendo NEOSSOLOS LITÓLICOS, NEOSSOLOS REGOLÍTICOS e CAMBISSOLOS. Assim esses solos foram agrupados todos em uma associação. Solos que apresentam processo hidromórfico, também foram agrupados em uma única associação.

As comparações entre o mapa digital com os levantamentos semidetalhados, ocorreram por meio de tabulações cruzadas, gerando-se matrizes de erros, da quais foram calculados os índices kappa de cada comparação, segundo Landis e Koch (1977). Segundo estes autores, com o índice kappa é possível avaliar a qualidade de um mapeamento, comparando-o a outro mapeamento existente. Este índice é calculado segundo a equação 6, isto é:

$$
k=\frac{\pi_{0}-\pi_{e}}{1-\pi_{e}}
$$

sendo, $\pi_{0}$ o total de acerto em relação ao total de observações, e $\pi_{e}$ é a probabilidade hipotética de certos ao acaso, usando os dados observados para calcular as probabilidades do observador classificar aleatoriamente cada categoria (Landis e Koch, 1977). Sua interpretação pode ser feita pelas seguintes classes: ruim, kappa $\leq 0$; fraco, $0<\mathrm{kappa} \leq 0.2$; razoável, $0.2<\mathrm{kappa} \leq 0.4 ;$ moderado, $0.4<\mathrm{kappa} \leq 0.6$; robusto, $0.6<\mathrm{kappa} \leq 0.8$; quase perfeito $0.8 \leq \mathrm{kappa} \leq 1.0$ (Landis e Koch, 1977).

A Figura 5 apresenta um fluxograma que resume todas as etapas realizadas, iniciadas com o pós-processamento das imagens de satélite de solo exposto, seguido pelas predições em subsuperfície de espectros de reflectância, depois pelas predições de atributos de solo aliados 
a validações das estimativas e por fim a geração do mapa digital de solos via lógica booleana com sua respectiva validação.

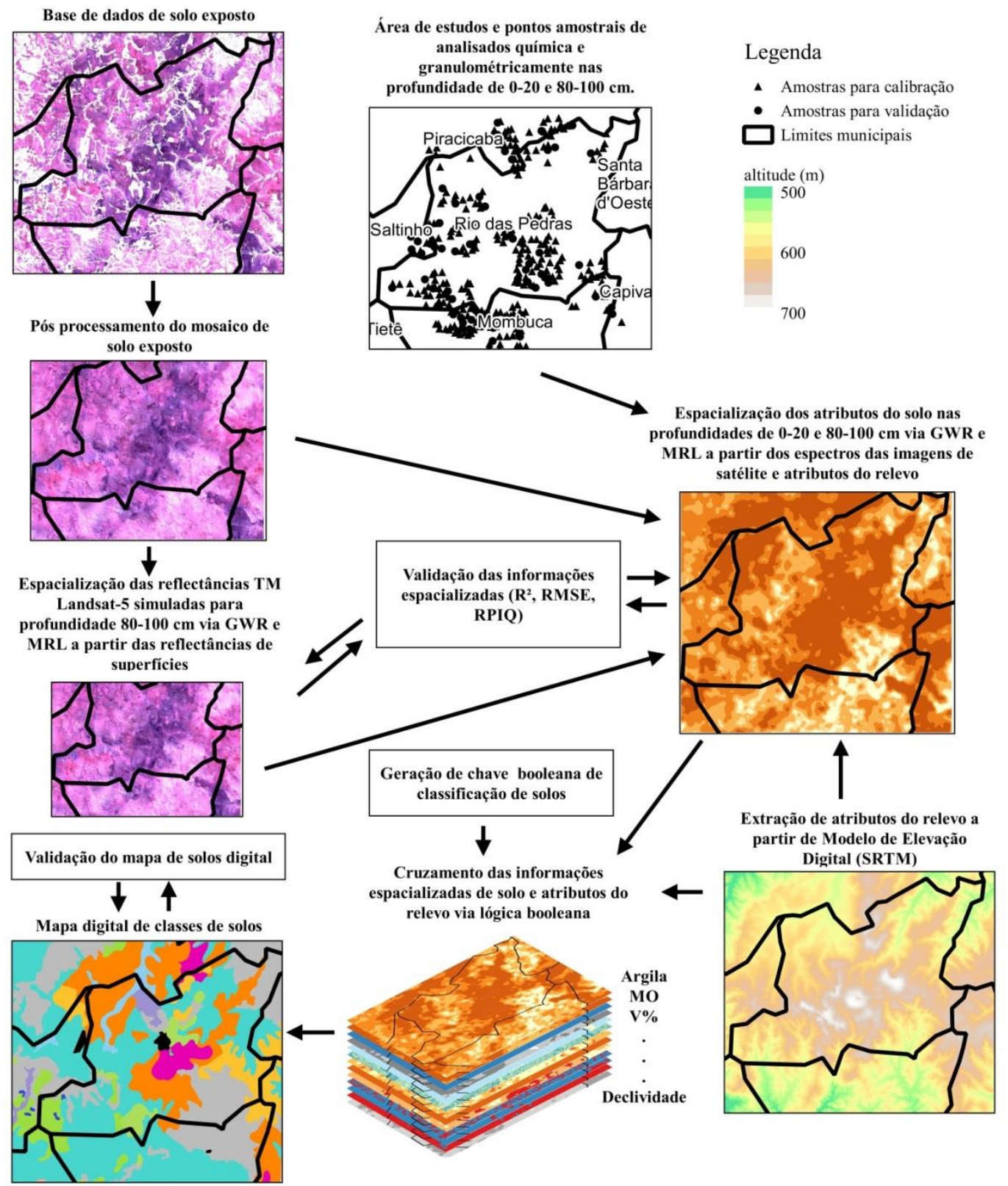

Figura 5. Fluxograma da metodologia de mapeamento e validação 


\section{RESULTADOS E DISCUSSÕES}

\subsection{Espacialização dos espectros das bandas TM landsat-5 simuladas em subsuperfície.}

A predição dos valores de reflectância de subsuperfície apresentaram bons resultados $\left(R^{2}>0,6\right.$ e RPIQ entre 2 e 2.5) (Tabela 1). A exceção foi a predição das bandas TM 1 simuladas pelo medo de predição $M R L$, que não apresentou-se confiável $\left(R^{2}<0.5\right)$. De maneira geral, quando utilizada as mesmas variáveis independentes, o método de predição GWR se mostrou ligeiramente superior ao método de predição MRL. O uso de variáveis independentes o MSEKGU se mostrou superior ao uso do MSEKG para a predição das reflectâncias em subsuperfície para as bandas TM 1, TM 2, TM 3 e TM4, enquanto o inverso foi observado para as bandas TM 5 e TM 7.

$\mathrm{Na}$ literatura não se observa trabalhos de predição de reflectância de subsuperfície a partir de reflectância em superfície, porém observa-se a similaridade das assinaturas espectrais entre dos horizontes em um mesmo perfil de solo obtidas em estudos utilizando sensores hiperespectrais de laboratório (Ben-dor et al., 2008; Araújo et al., 2015; Demattê et al., 2016), o que pode explicar resultados obtidos no presente trabalho, dado as boas correlações entre espectros nas duas profundidades.

\subsection{Espacialização dos atributos do solo}

A predição do teor de argila em superfície apresentou bons resultados $\left(\mathrm{R}^{2}\right.$ entre 0.5 e 0.75 e RPIQ entre 2 e 2.5) (Tabela 2), indo de acordo observado por Steinberg et al. (2016) na predição de argila a partir de imagens de sensor hiperespectral a bordo de avião pela por PLSR. Também vai de encontro ao obtido por Shabou et al. (2015), $\mathrm{R}^{2}$ de 0.65 via TM Landsat a partir da correlação de argila com um índice entre as bandas TM5 e TM7.

Os atributos químicos do solo em superficiais, matéria orgânica (m.o) e saturação por bases (v\%), apresentaram resultados não confiáveis ou ruins $\left(\mathrm{R}^{2}<0.5\right.$ e RPIQ entre 1.5 e 2.0) (Tabela 2). Valores baixos de $\mathrm{R}^{2}$ para esses atributos também foram observados por Bhering et al. (2016). Embora insatisfatórios pela observação do $\mathrm{R}^{2}$ e RPIQ, os valores de RMSE abaixo dos valores dos limites que separam caráter eutrófico/distrófico $(\mathrm{v} \%=50)$ e separam organossolos (m.o>13\%), permitem a utilização desses atributos espacializados na chave booleana de classificação de solos. 
Na comparação GWR/MRL, observa-se uma relativa superioridade do GWR para a predição destes atributos em superfície.

Tabela 1. Validação da predição da reflectância de subsuperfície a partir da reflectância imagem de satélite de superfície via métodos estatísticos multivariados

\begin{tabular}{|c|c|c|c|c|c|}
\hline Bandas TM Landsat-5 simuladas & Método de Predição & Variáveis independentes & $\mathrm{R}^{2}$ & RMSE & RPIQ \\
\hline TM 1 & GWR & $\mathrm{TM}^{1}{ }^{1}, \mathrm{TM}^{1}{ }^{1}, \mathrm{TM}^{1}{ }^{1} \mathrm{e}^{\mathrm{TM}} 5^{1}$ & 0.62 & 0.02 & 2.33 \\
\hline TM 1 & GWR & $\mathrm{TM}^{3}{ }^{3}, \mathrm{TM}^{3}, \mathrm{TM}^{3}{ }^{3}$ e TM $5^{3}$ & 0.60 & 0.02 & 2.22 \\
\hline TM 1 & MRL & $\mathrm{TM} 2^{5}, \mathrm{TM}^{5}, \mathrm{TM} 4^{5}$ e $\mathrm{TM} 5^{5}$ & 0.46 & 0.03 & 1.96 \\
\hline TM 1 & MRL & $\mathrm{TM} 2^{6}, \mathrm{TM}^{6}, \mathrm{TM} 4^{6}$ e $\mathrm{TM} 5^{6}$ & 0.44 & 0.03 & 1.92 \\
\hline TM 2 & GWR & $\mathrm{TM}^{2} ; \mathrm{TM}^{1}{ }^{1}, \mathrm{TM}^{1}{ }^{1} \mathrm{e} \mathrm{TM} 5^{1}$ & 0.72 & 0.03 & 2.70 \\
\hline TM 2 & GWR & $\mathrm{TM} 2^{4} ; \mathrm{TM}^{3}, \mathrm{TM}^{3} \mathrm{e} \mathrm{TM}^{3}$ & 0.66 & 0.03 & 2.45 \\
\hline TM 2 & MRL & $\mathrm{TM}^{2} ; \mathrm{TM}^{5}, \mathrm{TM}^{5} \mathrm{e} \mathrm{TM}^{5}$ & 0.60 & 0.04 & 2.27 \\
\hline TM 2 & MRL & $\mathrm{TM}^{4}, \mathrm{TM}^{6}, \mathrm{TM}^{6}{ }^{6} \mathrm{e} \mathrm{TM}^{6}$ & 0.58 & 0.04 & 2.18 \\
\hline TM 3 & GWR & $\mathrm{TM}^{2}, \mathrm{TM}^{2} ; \mathrm{TM}^{1}{ }^{1}, \mathrm{TM}^{1}{ }^{1}$ e TM $7^{1}$ & 0.69 & 0.04 & 2.35 \\
\hline TM 3 & GWR & $\mathrm{TM}^{4}, \mathrm{TM}^{4}, \mathrm{TM}^{3}, \mathrm{TM}^{3} \mathrm{e}^{\mathrm{T}} 7^{3}$ & 0.64 & 0.05 & 2.20 \\
\hline TM 3 & MRL & $\mathrm{TM}^{2}, \mathrm{TM}^{2}, \mathrm{TM} 4^{5}, \mathrm{TM}^{5}$ e TM$^{5}$ & 0.63 & 0.05 & 2.11 \\
\hline TM 3 & MRL & $\mathrm{TM} 3^{4}, \mathrm{TM} 2^{4}, \mathrm{TM} 4^{6}, \mathrm{TM}^{6}$ e $\mathrm{TM} 7^{6}$ & 0.62 & 0.05 & 2.09 \\
\hline TM 4 & GWR & $\mathrm{TM}^{2}, \mathrm{TM}^{2}{ }^{2}, \mathrm{TM}^{2}, \mathrm{TM}^{1}{ }^{1}$ e TM $7^{1}$ & 0.69 & 0.05 & 2.31 \\
\hline TM 4 & GWR & $\mathrm{TM}^{4}, \mathrm{TM}^{4}, \mathrm{TM}^{4}, \mathrm{TM}^{3}{ }^{3}$ e TM $7^{3}$ & 0.68 & 0.05 & 2.30 \\
\hline TM 4 & MRL & $\mathrm{TM}^{2}, \mathrm{TM}^{2}{ }^{2}$ e $\mathrm{TM} 5^{2}, \mathrm{TM}^{5}$ e $\mathrm{TM} 7^{5}$ & 0.61 & 0.07 & 1.90 \\
\hline TM 4 & MRL & $\mathrm{TM}^{4}, \mathrm{TM}^{4}{ }^{4}$ e $\mathrm{TM}^{4}, \mathrm{TM}^{6}{ }^{6}$ e $\mathrm{TM} 7^{6}$ & 0.58 & 0.06 & 1.94 \\
\hline TM 5 & GWR & $\mathrm{TM} 7^{4}$ e $\mathrm{TM} 5^{4}$ & 0.69 & 0.11 & 1.77 \\
\hline TM 5 & MRL & $\mathrm{TM}^{4}$ e TM$^{4}$ & 0.67 & 0.12 & 1.68 \\
\hline TM 5 & GWR & $\mathrm{TM}^{2}$ e TM5 $^{2}$ & 0.65 & 0.12 & 1.67 \\
\hline TM 5 & MRL & $\mathrm{TM}^{2}$ e TM$^{2}$ & 0.63 & 0.13 & 1.60 \\
\hline TM 7 & GWR & $\mathrm{TM} 7^{4}$ e TM $5^{4}$ & 0.67 & 0.05 & 2.49 \\
\hline TM 7 & MRL & $\mathrm{TM}^{4}$ e TM$^{4}$ & 0.66 & 0.06 & 2.47 \\
\hline TM 7 & GWR & $\mathrm{TM}^{2} \mathrm{e}^{\mathrm{TM}} 5^{2}$ & 0.64 & 0.06 & 2.39 \\
\hline TM 7 & MRL & $\mathrm{TM}^{2} \mathrm{e}^{\mathrm{TM}} 5^{2}$ & 0.64 & 0.06 & 2.34 \\
\hline
\end{tabular}

Tabela 2. Validação da espacialização dos atributos do solo em superfície pelos métodos estatísticos multivariados

\begin{tabular}{|c|c|c|c|c|c|c|}
\hline Atributo predito & $\begin{array}{l}\text { Método de } \\
\text { Predição }\end{array}$ & Variáveis independentes & $\begin{array}{l}\mathrm{N}^{\circ} \text { de amostras de } \\
\text { calibração/ validação }\end{array}$ & $\mathrm{R}^{2}$ & RMSE & RPIQ \\
\hline Argila $\left(\mathrm{gkg}^{-1}\right)$ & GWR & $\mathrm{TM}^{1}{ }^{1}, \mathrm{TM}^{1}{ }^{1}, \mathrm{TM}^{1}{ }^{1}, \mathrm{TM}^{1}{ }^{1}, \mathrm{TM}^{1}{ }^{1}$ & $264 / 64$ & 0.62 & 82.87 & 2.25 \\
\hline Argila $\left(\mathrm{gkg}^{-1}\right)$ & GWR & $\mathrm{TM} 7^{4}, \mathrm{TM}^{4}, \mathrm{TM} 4^{4}, \mathrm{TM} 3^{4}, \mathrm{TM} 2^{4}$ & $264 / 64$ & 0.53 & 91.88 & 2.03 \\
\hline Argila $\left(\mathrm{gkg}^{-1}\right)$ & MRL & $\mathrm{TM}^{1}{ }^{1}, \mathrm{TM}^{1}{ }^{1}, \mathrm{TM}^{1}{ }^{1}, \mathrm{TM}^{1}{ }^{1}, \mathrm{TM}^{1}$ & $264 / 64$ & 0.54 & 91.54 & 2.04 \\
\hline Argila $\left(\mathrm{gkg}^{-1}\right)$ & MRL & $\mathrm{TM} 7^{4}, \mathrm{TM}^{4}, \mathrm{TM} 4^{4}, \mathrm{TM} 3^{4}, \mathrm{TM} 2^{4}$ & $264 / 64$ & 0.56 & 88.83 & 2.10 \\
\hline M.O. $\left(\mathrm{gkg}^{-1}\right)$ & GWR & Argila_020_GWR ${ }^{2}$ TM71 & $264 / 64$ & 0.38 & 7.13 & 1.96 \\
\hline M.O. $\left(\mathrm{gkg}^{-1}\right)$ & GWR & Argila_020_GWR $2^{5} \mathrm{TM}^{4}$ & $264 / 64$ & 0.29 & 7.41 & 1.89 \\
\hline M.O. $\left(\mathrm{gkg}^{-1}\right)$ & MRL & Argila_020_MRL ${ }^{3} \mathrm{TM}^{1}$ & $264 / 64$ & 0.25 & 7.68 & 1.82 \\
\hline M.O. $\left(\mathrm{gkg}^{-1}\right)$ & MRL & Argila_020_MRL2 ${ }^{6}$, TM $^{4}$ & $264 / 64$ & 0.21 & 7.81 & 1.79 \\
\hline $\mathrm{V} \%$ & GWR & $\mathrm{TM}^{1}{ }^{1} \mathrm{TM}^{1}{ }^{-} \mathrm{TM}^{1}{ }^{1} \mathrm{TM}^{1}$ & $264 / 64$ & 0.31 & 14.83 & 1.62 \\
\hline $\mathrm{V} \%$ & GWR & $\mathrm{TM}^{4} \mathrm{TM}^{4}{ }^{4}{ }^{4} 4^{4} \mathrm{TM}^{4}$ & $264 / 64$ & 0.30 & 14.95 & 1.61 \\
\hline $\mathrm{V} \%$ & MRL & $\mathrm{TM}^{1}{ }^{1} \mathrm{TM}^{1}{ }^{1} \mathrm{TM} 4^{1}{ }^{1} \mathrm{TM} 5^{1}$ & $264 / 64$ & 0.20 & 16.04 & 1.50 \\
\hline $\mathrm{V} \%$ & MRL & $\mathrm{TM}^{4}, \mathrm{TM}^{4}, \mathrm{TM}^{4}{ }^{4}, \mathrm{TM}^{4}$ & $264 / 64$ & 0.24 & 15.82 & 1.52 \\
\hline
\end{tabular}

${ }^{1}$ Bandas TM MSEKG, ${ }^{2}$ Argila espacializada pelo método GWR a partir das bandas TM MSEKG; 3 Argila espacializada pelo método MRL a partir das bandas TM MSEKG; ${ }^{4}$ Bandas TM MSEKGU; ${ }^{5}$ Argila espacializada pelo método GWR a partir das bandas tm MSEKGU; ${ }^{6}$ Argila espacializada pelo método MRL a partir das bandas TM MSEKGU; MRL: Regressão Linear Multipla; GWR: Regressão Geograficamente Ponderada; MSEKG: Mosaico de solo exposto Krigado; MSEKGU: Mosaico de solo exposto unido com o mosaico de solo exposto Krigado; $\mathrm{R}^{2}$ : Coeficiente de determinação a 0.05 de significância; RMSE: Raiz Quadrada do Erro Médio Quadrático; RPIQ: Ratio of Performance/ Prediction to Interquartile. 
Os melhores resultados das variáveis independentes de origem do MSEKG em relação MSEKGU, podem ocorrer pelas transições de reflectâncias não suaves presentes no MSEKGU (Figura 6). Se observado em uma composição R:5, G:4 e B:3, as colorações em tons roxos mais escuros tem relação direta, por exemplo, com maiores teores de argila, enquanto na coloração em tons rosa mais claros pode indicar maiores teores de areia (Demattê et al., 2016). Assim, essas transições mais abruptas observadas no mosaico MSEKGU (Figura 6), podem ter influência negativa na qualidade das predições. Transições essas, que são suavizadas pelo efeito da krigagem na formação do mosaico MSEKG, onde valores de máximo da distribuição estatística dos dados tendem a ser subestimados e valores de mínimo superestimados (Da Rocha et al., 2007).

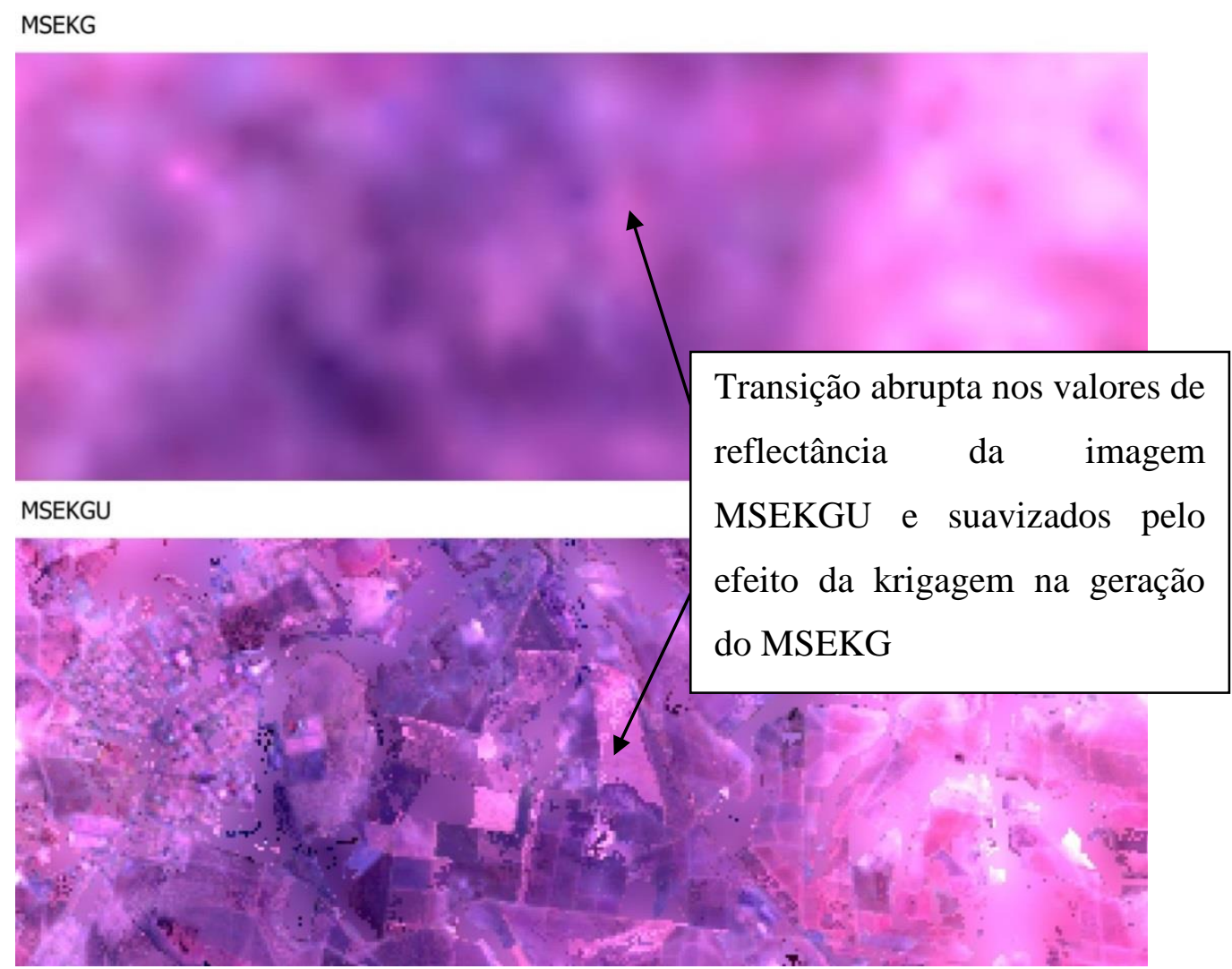

Figura 6. Zoom de aproximação sobre os mosaicos MSEKG e MSEKGU para demonstrar locais de transição dos valores de reflectância observados visualmente em composição falta cor R:5;G:4;B:3.

Em relação aos atributos de subsuperfície, a argila apresentou bons resultados de predição (Tabela 3), indo de acordo com o obtido por Steinberg et al. (2016). Entre as variáveis independentes e método de predição o melhor resultado obtido foi a partir do MSEKG pelo método GWR $\left(\mathrm{R}^{2}=0.63\right)$. Neste caso, a informação espectral de superfície apresentou maior correlação com a argila de subsuperfície, o que também pode ser explicado pelas similaridades das assinaturas espectrais ao longo de um perfil de um mesmo solo, como 
observado em Ben-dor et al. (2008); Araújo et al. (2015); Demattê et al. (2016). A argila estimada pelo método MRL a partir do MSEKGU, mostrou resultado não confiável $\left(\mathrm{R}^{2}<0.5\right)$. Já em relação aos atributos químicos (Al, V\%, m\% e CTC), a predição apresentou resultados não confiáveis ou ruins $\left(\mathrm{R}^{2}<0.5\right.$ e RPIQ<2) (Tabela 3). Apesar disso, como discutido para a predição dos atributos químicos em superfície, o RMSE apresentou valores abaixo da classe limiar que é definido na chave booleana para a separação das classes de solo, o que também permite a utilização desses atributos nessa chave booleana. Na predição de todos os atributos observados na tabela 3, observa-se superioridade do método de predição GWR em relação ao MRL.

Tabela 3. Validação da espacialização dos atributos do solo em subsuperfície pelos métodos estatísticos multivariados

\begin{tabular}{|c|c|c|c|c|c|c|}
\hline Atributo & $\begin{array}{l}\text { Método de } \\
\text { predição }\end{array}$ & Variáveis independentes & $\begin{array}{l}\mathrm{N}^{\circ} \text { de amostras } \\
\text { de calibração/ } \\
\text { validação }\end{array}$ & $\mathrm{R}^{2}$ & RMSE & RPIQ \\
\hline Argila (gkg-1) & GWR & $\mathrm{TM}^{5}, \mathrm{TM}^{5}$ e $\mathrm{TM} 4^{5}$ & $258 / 64$ & 0.63 & 88.24 & 2.68 \\
\hline Argila (gkg-1) & GWR & $\mathrm{TM}^{6}, \mathrm{TM}^{6}$ e $\mathrm{TM} 4^{6}$ & $258 / 64$ & 0.54 & 101.43 & 2.33 \\
\hline Argila (gkg-1) & MRL & TM $7^{5}, \mathrm{TM}^{5}$ e TM $4^{5}$ & $258 / 64$ & 0.55 & 97.66 & 2.42 \\
\hline Argila (gkg-1) & MRL & TM $7^{6}, \mathrm{TM}^{6}$ e TM $4^{6}$ & $258 / 64$ & 0.43 & 112.85 & 2.09 \\
\hline $\mathrm{Al}\left(\mathrm{mmolc} / \mathrm{dm}^{3}\right)$ & GWR & $\mathrm{CTC}^{1}, \mathrm{~V} \%^{1}, \mathrm{~m} \%^{1}$ & $258 / 64$ & 0.32 & 11.95 & 1.51 \\
\hline $\mathrm{Al}\left(\mathrm{mmolc} / \mathrm{dm}^{3}\right)$ & GWR & $\mathrm{CTC}^{2}, \mathrm{~V} \%{ }^{2}, \mathrm{~m} \%^{2}$ & $258 / 64$ & 0.21 & 13.22 & 1.36 \\
\hline $\mathrm{Al}\left(\mathrm{mmolc} / \mathrm{dm}^{3}\right)$ & MRL & $\mathrm{CTC}^{3}, \mathrm{~V} \%^{3}, \mathrm{~m} \%^{3}$ & $258 / 64$ & 0.36 & 11.73 & 1.53 \\
\hline $\mathrm{Al}\left(\mathrm{mmolc} / \mathrm{dm}^{3}\right)$ & MRL & $\mathrm{CTC}^{4}, \mathrm{~V} \%{ }^{4}, \mathrm{~m} \%^{4}$ & $258 / 64$ & 0.07 & 14.56 & 1.24 \\
\hline CTC $\left(\mathrm{mmolc} / \mathrm{dm}^{3}\right)$ & GWR & TM5 $^{1}$, TM $^{1}$, Argila $^{1}$ & $258 / 64$ & 0.35 & 69.82 & 0.89 \\
\hline $\mathrm{CTC}\left(\mathrm{mmolc} / \mathrm{dm}^{3}\right)$ & GWR & $\mathrm{TM}^{2}, \mathrm{TM}^{2}$, Argila $^{2}$ & $258 / 64$ & 0.29 & 71.73 & 0.87 \\
\hline $\mathrm{CTC}\left(\mathrm{mmolc} / \mathrm{dm}^{3}\right)$ & MRL & TM5 $^{3}$, TM $^{3}$, Argila $^{3}$ & $258 / 64$ & 0.06 & 83.26 & 0.75 \\
\hline $\mathrm{CTC}\left(\mathrm{mmolc} / \mathrm{dm}^{3}\right)$ & MRL & $\mathrm{TM}^{4}, \mathrm{TM}^{4}$, Argila $^{4}$ & $258 / 64$ & 0.02 & 84.37 & 0.74 \\
\hline $\mathrm{m} \%$ & GWR & $\mathrm{TM}^{1}, \mathrm{TM}^{1}, \mathrm{TM}^{1}, \mathrm{~V} \%{ }^{1}$ & $258 / 64$ & 0.27 & 17.01 & 1.35 \\
\hline $\mathrm{m} \%$ & GWR & $\mathrm{TM}^{2}, \mathrm{TM}^{2}, \mathrm{TM} 4^{2}, \mathrm{~V} \%{ }^{2}$ & $258 / 64$ & 0.23 & 17.47 & 1.32 \\
\hline $\mathrm{m} \%$ & MRL & $\mathrm{TM}^{3}, \mathrm{TM}^{3}, \mathrm{TM}^{3}, \mathrm{~V} \%^{3}$ & $258 / 64$ & 0.11 & 19.16 & 1.20 \\
\hline $\mathrm{m} \%$ & MRL & $\mathrm{TM}^{4}, \mathrm{TM}^{4}, \mathrm{TM}^{4}, \mathrm{~V} \%{ }^{4}$ & $258 / 64$ & 0.17 & 18.31 & 1.26 \\
\hline V\% & GWR & TPI, SLH, TM $7^{5}$, TM $4^{5}$, VLD e SAR & $258 / 64$ & 0.12 & 20.42 & 1.75 \\
\hline V\% & GWR & TPI, SLH, TM7 $7^{6}, \mathrm{TM}^{6}$, VLD, SAR & $258 / 64$ & 0.14 & 20.19 & 1.77 \\
\hline V\% & MRL & TPI, SLH, TM $7^{5}, \mathrm{TM} 4^{5}, \mathrm{VLD}$ e SAR & $258 / 64$ & 0.05 & 21.09 & 1.70 \\
\hline $\mathrm{V} \%$ & MRL & TPI, SLH, TM7 $7^{6}, \mathrm{TM}^{6}, \mathrm{VLD}, \mathrm{SAR}$ & $258 / 64$ & 0.07 & 20.85 & 1.71 \\
\hline \multicolumn{7}{|c|}{$\begin{array}{l}\text { atributo ou banda TM LandSat-5 espacializados pelo método GWR a partir das bandas TM MSEKG; }{ }^{2} \text { atributo ou banda } \\
\text { TM LandSat-5 espacializados pelo método GWR a partir das bandas TM MSEKGU; }{ }^{3} \text { atributo ou banda TM LandSat-5 } \\
\text { espacializados pelo método MRL a partir das bandas TM MSEKG; }{ }^{4} \text { atributo ou banda TM LandSat-5 espacializados pelo } \\
\text { método MRL a partir das bandas TM MSEKGU; }{ }^{5} \text { Bandas TM MSEKG; }{ }^{6} \text { Bandas TM MSEKGU; SLH: Slope Height; VLD: } \\
\text { Valley Depth; SAR: Surface Area; MRL: Regressão Linear Multipla; GWR: Regressão Geograficamente Ponderada; } \\
\text { MSEKG: Mosaico de solo exposto Krigado; MSEKGU: Mosaico de solo exposto unido com o mosaico de solo exposto } \\
\text { Krigado; R }{ }^{2} \text { Coeficiente de determinação a 0.05 de significância; RMSE: Raiz Quadrada do Erro Médio Quadrático; RPIQ: } \\
\text { Ratio of Performance/ Prediction to Interquartile. }\end{array}$} \\
\hline
\end{tabular}

A predição do atributo ferro total, que foi realizada apenas pelo método MRL e a avaliada por validação cruzada do tipo leave-one-out (tabela 3), apresentou o bom resultado para $R^{2}$ (0.72), o que vai de acordo com observações de Nanni e Demattê (2006), ruim para o RPIQ (1.69), mas com RMSE=5.88\%, que é abaixo do limite para determinar caráter férrico (18\%), o que permite a utilização desse atributo na chave booleana. Outra observação importante é que a variável preditora para este atributo, foi o MSEKGU2, o que demonstra importância na espacialização dos espectros de reflectância em subsuperfície. 
Os atributos do solo matiz, valor e croma apresentaram bons resultados para $\mathrm{R}^{\mathbf{2}} \mathrm{e}$ muito bons para RPIQ quando tiveram como variável independente o MSEKGU2 (Tabela 3). Matiz obteve bons resultados $\mathrm{R}^{2}=0.57$ e RPIQ=2.07, valor e croma obtiveram de bons a muito bons resultados, $\mathrm{R}^{2}=0.74, \mathrm{R}^{2}=0.67, \mathrm{RIPQ}=3.04$ e $\mathrm{RPIQ}=2.87$, respectivamente (Tabela 3). Tais resultados vão de encontro as boas correlações entre reflectância e cor do sistema munsell observadas por Escadafal et al. (1989); Post et al. (1994); Mathieu et al. (1998). Nestas predições, observa-se que o GWR apresentou o melhor desempenho para estimativa do matiz, sendo ligeiramente inferior a combinação MRL/MSEKGU2 para valor e croma (Tabela 3), o que pode demonstrar que apenas a correlação desses atributos com os valores espectrais podem ser suficiente para a suas predições.

Os melhores resultados da predição de atributos ferro, matiz, valor e croma a partir das informações MSKGU2 originadas do MSKGU, diferentemente do observado para predição dos atributos argila, CTC, m\%, V\% e Al, pode sugerir, que as transições abruptas dos valores de reflectância não são suficientes para interferir nas de atributos do solos que apresentam maiores correlações com as bandas que se situam nos comprimentos de onda do visível (TM 1, TM 2 e TM 3).

Vários trabalhos têm relatado que dados espectrais obtidos por sensores a bordo de satélites diferenciam muitas classes pedológicas, apesar de detectar somente a camada superficial do solo. De fato, Nanni et al. (2014) demonstram que imagem de satélite discrimina classes de pedológicas. Zeng et al. (2016), observaram que a informação superficial infere questões de subsuperfície. Tais relatos corroboram os resultados da reflectância de superfície como forma de inferir a reflectância de subsuperfície, com $\mathrm{R}^{2}$ acima de 0.5 observados nas tabelas 1,3 e 4 .

A quantificação de atributos via espectros não é novo. Soriano-Disla et al. (2014) fizeram forte trabalho de referência em literatura sobre o tema. Relatam inclusive, a melhor quantificação de atributos físicos que químicos. De fato, Lacerda et al. (2016) demonstraram a forte correlação de espectros com granulometria. Tais observações corroboram com as quantificações dos atributos deste trabalho.

\subsection{Atributos utilizados para classificação dos solos}

Para os teores de argila, observa-se vários locais com teores de argila em superfície bem menores que os teores de argila em subsuperfície, o que infere na presença de Argissolos (Figuras 7 a, b). A maior parte da região as áreas são eutróficas (V>50\%) (figura 7c) e em subsuperfície a maior parte da área é distrófica $(\mathrm{V}<50 \%)($ figura $7 \mathrm{~d})$. Isso se deve pelo manejo 
do solo pela prática de calagem nas áreas agrícolas, que ocorre principalmente em superfície elevando os valores de V\% para níveis eutróficos. A distribuição dos teores de matéria orgânica, que ocorrem abaixo de $60 \mathrm{gkg}^{-1}$, e que indica ausencia de Organossolos na região, e a presença na maior parte da área com teores entre 13 e $60 \mathrm{gkg}^{-1}$ de matéria orgânica, aliado a eutrofismo da região, indica uma grande ocorrência do horizonte diagnóstico superficial A chernozemico (figura 7e). Os teores de ferro são extremamente variáveis na região, com pequenas áreas com quantidade que indicam carater férrico (>18 mg/dm³) (Figura 7f).

Tabela 4. Validação da espacialização dos atributos de cor do solo e ferro em subsuperfície pelos métodos estatísticos multivariados

\begin{tabular}{|c|c|c|c|c|c|c|}
\hline Atributo & Método de predição & Variáveis independents & $\mathrm{N}^{\circ}$ de amostras de calibração/ validação & $\mathrm{R}^{2}$ & RMSE & RPIQ \\
\hline Croma & MRL & $\mathrm{TM} 1^{3}, \mathrm{TM}^{3}, \mathrm{TM}^{3}$ & $258 / 64$ & 0.67 & 0.51 & 2.87 \\
\hline Croma & GWR & $\mathrm{TM}^{1}{ }^{1}, \mathrm{TM} 2^{1}, \mathrm{TM}^{1}{ }^{1}$ & $258 / 64$ & 0.63 & 0.52 & 2.78 \\
\hline Croma & GWR & $\mathrm{TM} 1^{2}, \mathrm{TM} 2^{2}, \mathrm{TM}^{2}$ & $258 / 64$ & 0.43 & 0.65 & 2.24 \\
\hline Croma & MRL & $\mathrm{TM}^{4}, \mathrm{TM}^{4}, \mathrm{TM}^{4}$ & $258 / 64$ & 0.34 & 0.69 & 2.09 \\
\hline $\mathrm{Fe}_{2} \mathrm{O}_{3}$ & MRL* & $\mathrm{TM}^{1}{ }^{1}, \mathrm{TM}^{1}{ }^{1}, \mathrm{TM}^{1}{ }^{1}, \mathrm{TM}^{1}$ & 11 & 0.72 & 5.88 & 1.69 \\
\hline $\mathrm{Fe}_{2} \mathrm{O}_{3}$ & MRL* & $\mathrm{TM}^{2}, \mathrm{TM}^{2}, \mathrm{TM}^{2}, \mathrm{TM}^{2}$ & 11 & 0.56 & 7.17 & 1.39 \\
\hline Matiz & GWR & $\mathrm{TM}^{1}{ }^{1}, \mathrm{TM} 2^{1}, \mathrm{TM}^{1}{ }^{1}, \mathrm{TM}^{1}{ }^{1}$ & $258 / 64$ & 0.57 & 1.28 & 2.07 \\
\hline Matiz & GWR & $\mathrm{TM}^{2}, \mathrm{TM}^{2}, \mathrm{TM}^{2}, \mathrm{TM}^{2}$ & $258 / 64$ & 0.49 & 1.40 & 1.90 \\
\hline Matiz & MRL & $\mathrm{TM} 1^{3}, \mathrm{TM} 2^{3}, \mathrm{TM}^{3}, \mathrm{TM} 4^{3}$ & $258 / 64$ & 0.45 & 1.43 & 1.86 \\
\hline Matiz & MRL & $\mathrm{TM} 1^{4}, \mathrm{TM} 2^{4}, \mathrm{TM}^{4}, \mathrm{TM}^{4}$ & $258 / 64$ & 0.30 & 1.60 & 1.66 \\
\hline Valor & MRL & $\mathrm{TM} 1^{3}, \mathrm{TM}^{3}, \mathrm{TM}^{3}$ & $258 / 64$ & 0.74 & 0.25 & 3.04 \\
\hline Valor & GWR & $\mathrm{TM}^{1}{ }^{1}, \mathrm{TM} 2^{1}, \mathrm{TM} 3^{1}$ & $258 / 64$ & 0.73 & 0.26 & 2.96 \\
\hline Valor & GWR & $\mathrm{TM} 1^{2}, \mathrm{TM} 2^{2}, \mathrm{TM}^{2}$ & $258 / 64$ & 0.64 & 0.30 & 2.59 \\
\hline Valor & MRL & $\mathrm{TM}^{4}{ }^{4}, \mathrm{TM} 2^{4}, \mathrm{TM}^{4}{ }^{4}$ & $258 / 64$ & 0.60 & 0.32 & 2.45 \\
\hline
\end{tabular}

*Método de Validação Cross validation, leave one out; ${ }^{1}$ MSEKGU2 via GWR; ${ }^{2}$ MSEKG2 via GWR; ${ }^{3}$ MSEKGU2 via MRL; ${ }^{4}$ MSEKG2 via MRL; MRL: Regressão Linear Multipla; GWR: Regressão Geograficamente Ponderada; MSEKG: Mosaico de solo exposto Krigado; MSEKG2: Mosaico de solo exposto simulado em subsuperficie a partir do MSEKG; MSEKGU: Mosaico de solo exposto unido com o mosaico de solo exposto Krigado; MSEKGU2: Mosaico de solo exposto simulado em subsuperficie a partir do MSEKGU; R²: Coeficiente de determinação a 0.05 de significância; RMSE: Raiz Quadrada do Erro Médio Quadrático; RPIQ: Ratio of Performance/ Prediction to Interquartile.

A saturação por alumínio, apresenta-se na maior parte da área com valores abaixo de $40 \%$, assim como os teores de alumínio abaixo de $40 \mathrm{mmolc} / \mathrm{dm}^{3}$, que apresenta poucas áreas que apresentam o carater alítico, importante na discriminação das classe de nitossolo (Figuras 8 a,b). A CTC apresenta-se com valores bastante variáveis (Figura 8c), mas com bastante áreas com valores acima de $150 \mathrm{mmolc} / \mathrm{dm}^{3}$, que pode ser áreas com presença de Neossolos Regolíticos.

A cor do solo, segundo os sistema munsell, apresenta em sua maior parte com matiz entre 2.5 e $5 \mathrm{YR}$ e valor e croma entre 3 e 5 . Isso indica que na região o segundo nivel categórico, na maior parte da área de estudo, para classificação de Argissolos e Latossolos tende a ser Vermelho Amarelo (Figuras $8 \mathrm{~d}$, e, f).

Nota-se que o artibuto Normalize Height discriminou vários canais de drenagem, que aliados a declividade plana, indicam a presença de solos aluviais (Neossolos Flúvicos, Planossolos, Luvissolos e Gleissos)(Figura 9a). Em termos de declividade, a região se apresenta com o relevo em sua maior parte nas classes plana, suave ondulado e ondulado, com 
isso os limiares de declividade para separação de Nitossolo de Latossolo tende a ser mais baixo, assim como a ocorrência de Cambissolos e Neossolos Litólicos em declividade abaixo de 20\%(Figura 9a).

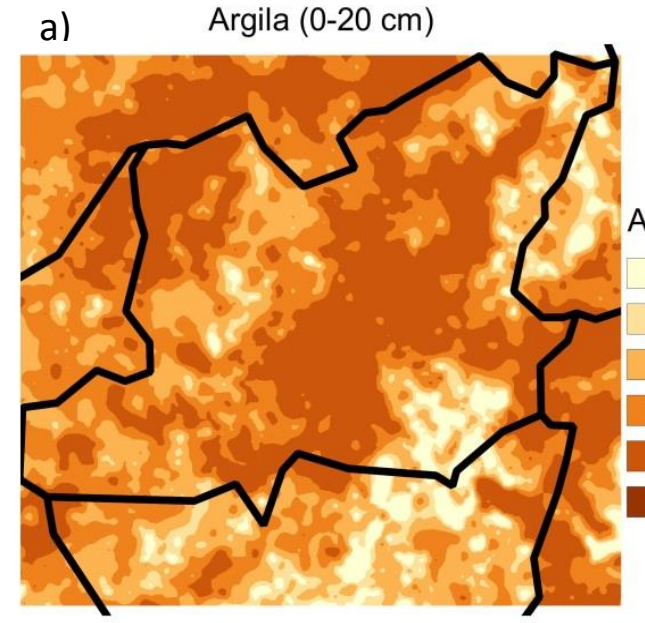

c)

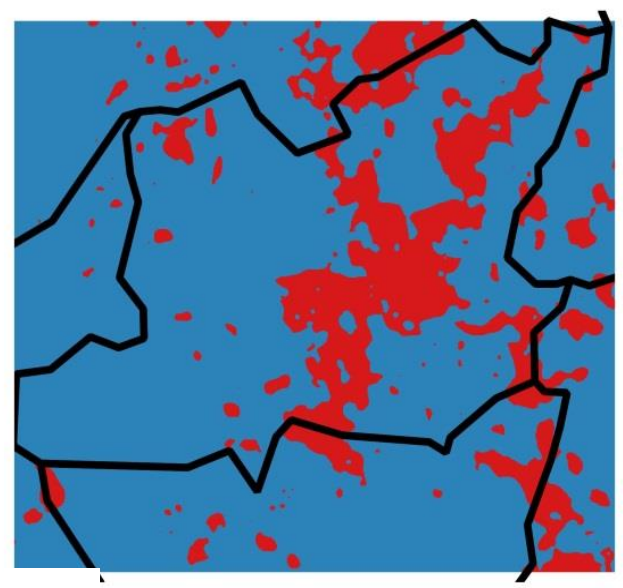

e)

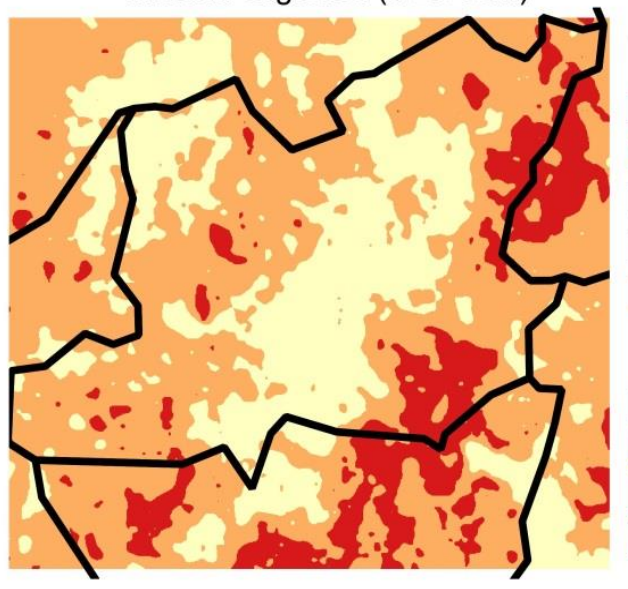

Argila_A

$<=100(\mathrm{~g} / \mathrm{kg})$ $100-150(\mathrm{~g} / \mathrm{kg})$ $150-250(\mathrm{~g} / \mathrm{kg})$ $250-350(\mathrm{~g} / \mathrm{kg})$ $350-650(\mathrm{~g} / \mathrm{kg})$ $>650(\mathrm{~g} / \mathrm{kg})$

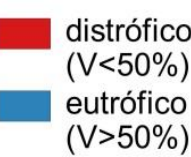

Teores de M.O. $<=13(\mathrm{~g} / \mathrm{kg})$

$13-20(\mathrm{~g} / \mathrm{kg})$ $20-60(\mathrm{~g} / \mathrm{kg})$ $60-120(\mathrm{~g} / \mathrm{kg})$ $120-1000(\mathrm{~g} / \mathrm{kg})$ Ferro total

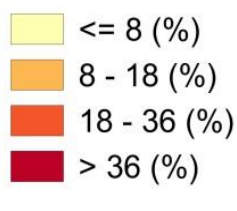

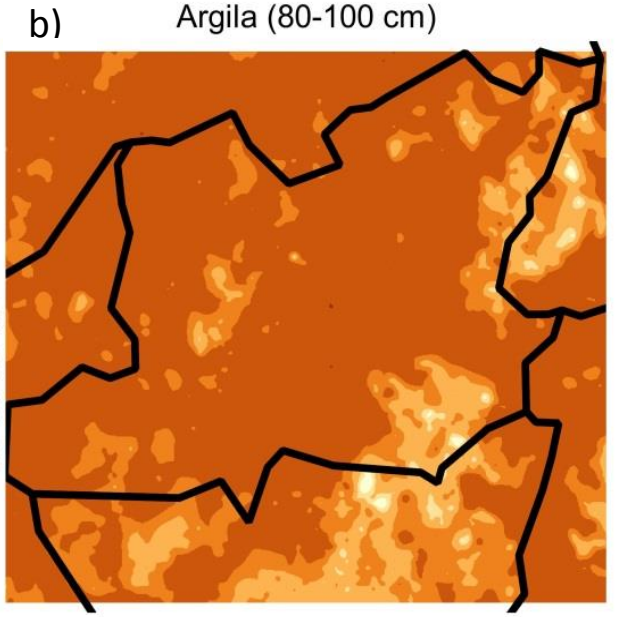

d) V\% (80-100 cm)

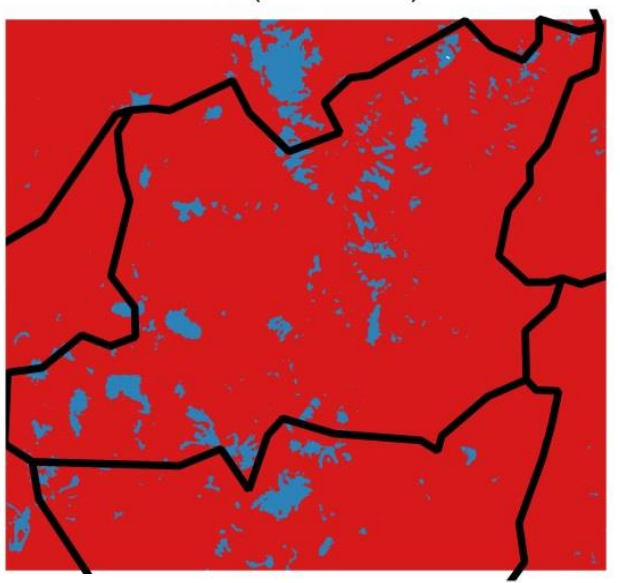

f)

Ferro total $(80-100 \mathrm{~cm})$

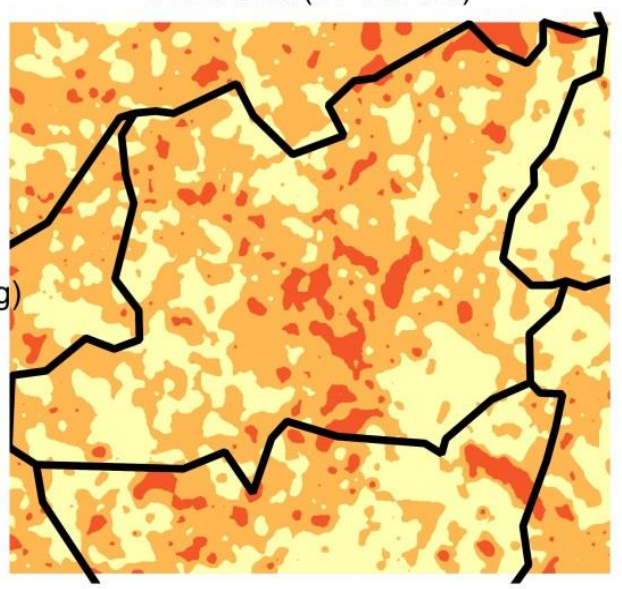

Figura 7. Atributos espacializados para utilização na chave booleana de classificação de solos: a. argila $0-20 \mathrm{~cm}$; b. argila 80-100 cm; c. V\% 0-20 cm; d. V\% 80-100 cm; e. matéria orgânica 0-20 cm; e f. ferro total 80-100 cm. 


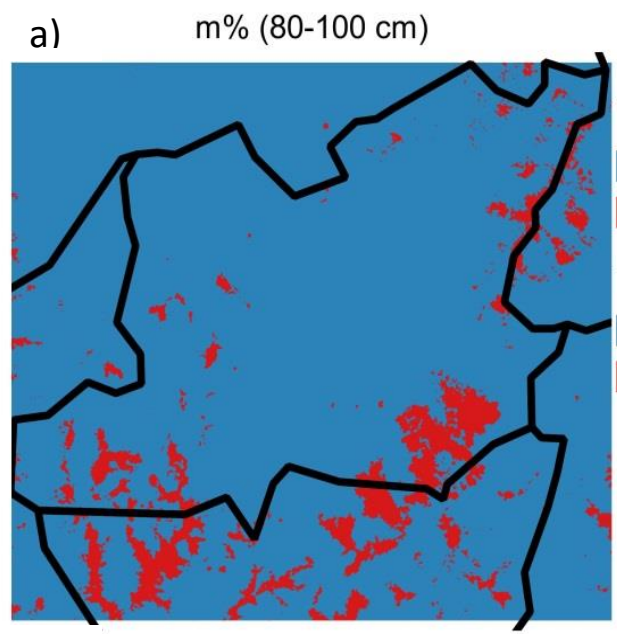

c)

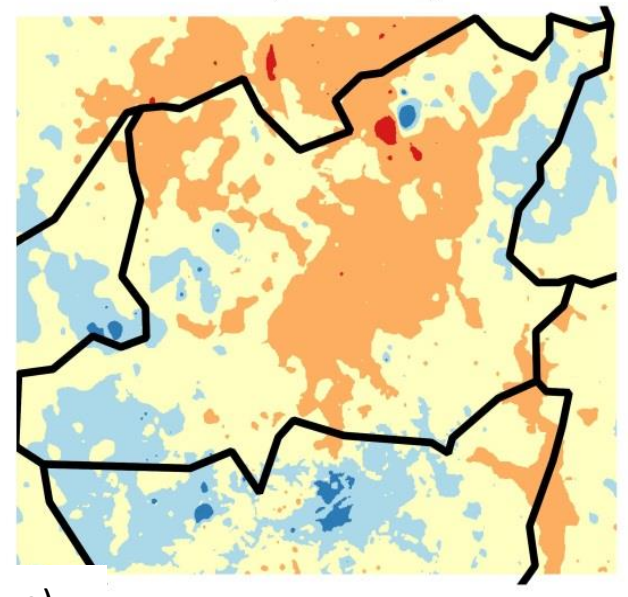

e)

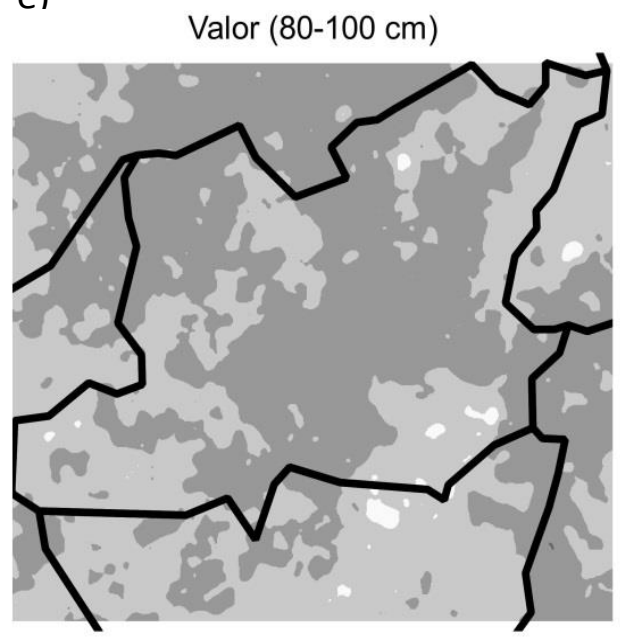

Teores de $\mathrm{m} \%$

$<=40(\%)$

$\square 40(\%)$

Teores de Al

$<=40\left(\mathrm{mmolc} / \mathrm{dm}^{3}\right)$

$>40\left(\mathrm{mmolc} / \mathrm{dm}^{3}\right)$

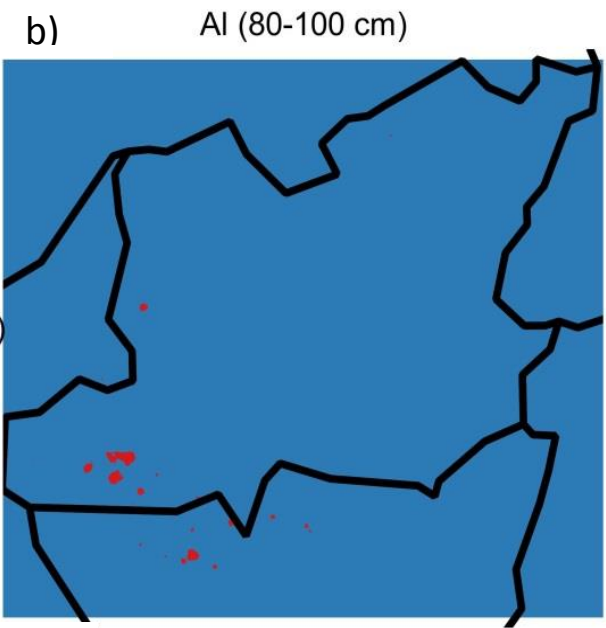

d)

Matiz (80-100 cm)

CTC $\left(\mathrm{mmolc} / \mathrm{dm}^{3}\right)$

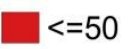

50-100

100-150

150-200

$>200$

Matiz

$<=2.5 \mathrm{YR}$

2.5-5YR

5-7.5YR

$>7.5 \mathrm{YR}$

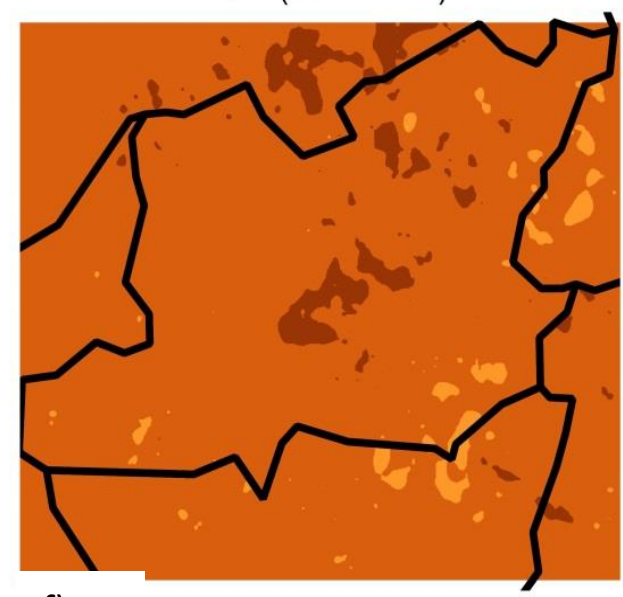

f)

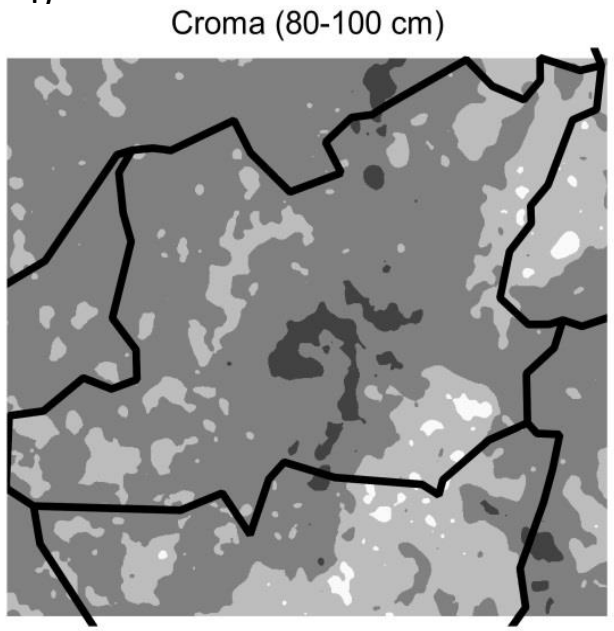

Figura 8. Atributos espacializados para utilização na chave booleana de classificação de solos: a. argila 0-20 cm; b. argila 80-100 cm; c. V\% 0-20 cm; d. V\% 80-100 cm; e. matéria orgânica 0-20 cm; e ferro $\left(\mathrm{Fe}_{2} \mathrm{O}_{3}\right)$ 80-100 cm. 
a) Normalize Height

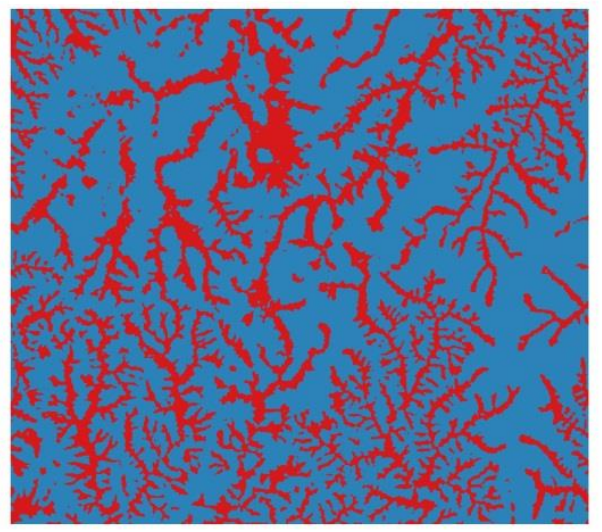

b)

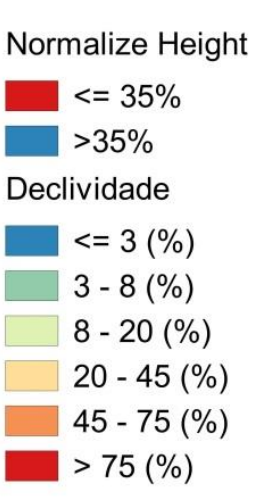

Declividade

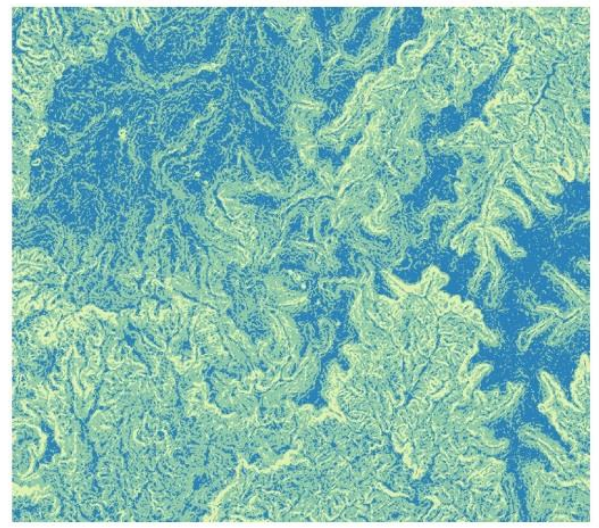

Figura 9. Atributos do relevo para utilização na chave booleana de classificação de solos: Normalize Height e Declividade.

\subsection{Mapeamento digital e validação}

No mapeamento digital de solos (Figura 10) via lógica booleana obteve-se as classes de solos LATOSSOLOS VERMELHOS (LV), LATOSSOLOS VERMELHO AMARELOS (LVA), CHERNOSSOLOS (M), NITOSSOLOS VERMELHOS (NV), NITOSSOLOS HÁPliCOS (NX), ARGISSOLOS AMARELOS (PA), ARGISSOLOS BRUNO ACINZENTADOS (PBAC), ARGISSOLOS ACINZENTADOS (PAC), ARGISSOLOS VERMELHOS (PV), ARGISSOLOS VERMELHO AMARELOS (PVA), Associação NEOSSOLOS FLÚVICOS + GLEISSOLOS (RF+G), Associação NEOSSOLOS LITÓLICOS + CAMBISSOLOS (RL+C), NEOSSOLOS QUARTZARÊNICOS (RQ), NEOSSOLOS REGOLÍTICOS (RR), e LUVISSOLOS (T). Dessas classes obtiveram-se algumas subdivisões de acordo com as seguintes características: eutróficos, distróficos, eutroférricos, distroférricos, abrupticos (Argissolos), psamíticos (Latossolos), muito arenosos (<10\% de argila), arenosos (10-15\% de argila), médio arenosos (15-25\% de argila), médio argilosos (25-35\% de argila), argilosos (35-65\% de argila) e muito argilosos ( $>65 \%$ de argila).

Dos solos encontrados $31.27 \%$ foram compostos por LATOSSOLOS VERMELHO AMARELOS distróficos argilosos, $9.12 \%$ o por associação NEOSSOLOS FLÚVICOS + GLEISSOLOS distróficos argilosos, $8.24 \%$ por ARGISSOLOS VEMELHO AMARELOS distróficos argilosos, $5.91 \%$ por associações de NEOSSOLOS LITÓLICOS + CAMBISSOLOS distróficos argilosos, $5.14 \%$ de NITOSSOLOS HÁPLICOS distróficos argilosos, 4.92\% de ARGISSOLOS VERMELHO AMARELOS distróficos médio argilosos, 4.85\% LATOSSOLOS VERMELHO AMARELOS distróficos médio argilosos, 3.66\% 
LATOSSOLOS VERMELHO AMARELOS distroférricos argilosos, e os restantes abaixo de $3 \%$ de ocorrência. O Anexo B apresenta as porcentagens dessas e outras classes de solos encontradas.

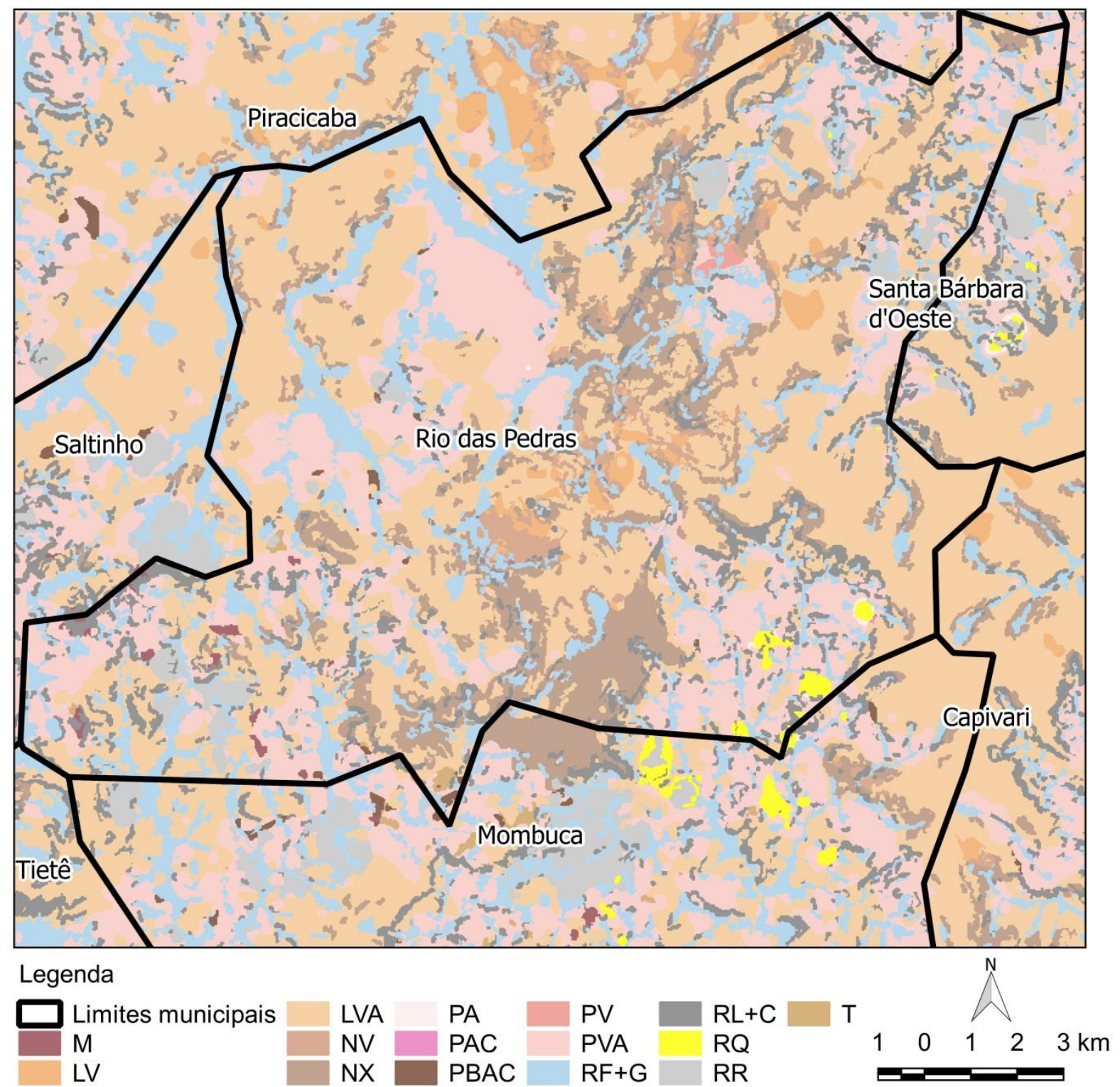

Figura 10. Mapas de solo com classes simplificadas gerado pela regra booleana e mapas de solos para comparação. LV: LATOSSOLOS VERMELHOS; LVA: LATOSSOLOS VERMELHO AMARELOS; M: CHERNOSSOLOS (M); NV: NITOSSOLOS VERMELHOS; NX: NITOSSOLOS HÁPLICOS; PA: ARGISSOLOS AMARELOS; PBAC: ARGISSOLOS BRUNO ACINZENTADOS; PAC: ARGISSOLOS ACINZENTADOS; PV: ARGISSOLOS VERMELHOS; PVA: ARGISSOLOS VERMELHO AMARELOS; RF+G: Associação NEOSSOLOS FLÚVICOS + GLEISSOLOS; RL+C: Associação NEOSSOLOS LITÓLICOS + CAMBISSOLOS; RQ: NEOSSOLOS QUARTZARÊNICOS; RR: NEOSSOLOS REGOLÍTICOS; e T: LUVISSOLOS. 
No mapa digital de solos, observou-se a distribuição das classes de solo LVA, PVA, $\mathrm{RF}+\mathrm{G}$ por toda a área de estudo, uma grande área de $\mathrm{NX}$ ao sul e uma área significava com RQ ao sudeste de Rio das Pedras (Figura 10). Descritivamente ocorreram muitas correspondência das classes de solos LV, LVA, RR, PVA, NX com os mapas de solos de referência, mas também muitas confusões entre as classes de solos. A análise estatística pelo índice kappa (Tabelas 5 e 6), evidencia essas confusões. Pelo kappa, observa-se pela comparação com os mapas de solos de referência, que a classificação foi razoável em três tipos (kappa entre 20 e 40) de comparação e fraca em um tipo de comparação (kappa $13.17 \%$ ), segundo a interpretação recomentada por (Landis e Koch, 1977).

Na comparação até o primeiro nível, com o mapa na escala de 1:20.000, observa-se kappa de $34.65 \%$ e acurácia global de $54.46 \%$ (Tabela 5). Os maiores acertos foram para as classes de Latossolos (acurácia entre 60 e 84\%), e as classes associadas P+M (acurácia entre 40-78\%). Os menores acertos foram paras as classes associadas de $\mathrm{RF}+\mathrm{G}+\mathrm{T}+\mathrm{S}$, e houve grande confusão entre as classes de $\mathrm{N}$ (acurácia entre 22 e $43 \%$ ) com L ou P+M.

Na comparação até o primeiro nível com o mapa na escala de 1:100.000, observa-se kappa de $25.14 \%$ e acurácia global de $41.74 \%$ (Tabela 5). Similar à comparação anterior, os Latossolos apresentaram os maiores acertos (acurácia entre 52 a 76\%), seguido pela associação $\mathrm{P}+\mathrm{C}$ (acurácia entre 27 e 52\%). Os solos hidromórficos $(\mathrm{RF}+\mathrm{G}+\mathrm{T}+\mathrm{S})$ apresentaram os menores valores (acurácia entre 8 e $46 \%$ ).

Tabela 5. Matriz de erro para comparação das classificações até $1^{\mathrm{a}}$ ordem entre o mapa digital de solos e levantamentos pedológicos semidetalhados.

\begin{tabular}{|c|c|c|c|c|c|c|}
\hline \multicolumn{7}{|c|}{ Levantamentos pedológicos (escala 1:20.000), kappa $=34.65 \%$ e Acurácia global $=54.46 \%$. } \\
\hline Classes $1^{\mathrm{a}}$ Nível Categórico Parcial & $\mathrm{L}$ & $\mathrm{N}$ & $\mathrm{P}+\mathrm{M}$ & $\mathrm{RF}+\mathrm{G}+\mathrm{T}+\mathrm{S}$ & $\mathrm{RL}+\mathrm{C}+\mathrm{RR}+\mathrm{RQ}$ & Acurácia $(\%)$ \\
\hline $\mathrm{L}$ & 1792 & 283 & 36 & 39 & 4 & 83.19 \\
\hline $\mathrm{N}$ & 134 & 137 & 3 & 31 & 17 & 42.55 \\
\hline $\mathrm{P}+\mathrm{M}$ & 653 & 144 & 915 & 190 & 334 & 40.92 \\
\hline $\mathrm{RF}+\mathrm{G}+\mathrm{T}+\mathrm{S}$ & 40 & 6 & 26 & 32 & 4 & 29.63 \\
\hline $\mathrm{RL}+\mathrm{C}+\mathrm{RR}+\mathrm{RQ}$ & 316 & 38 & 202 & 70 & 198 & 24.03 \\
\hline \multicolumn{7}{|c|}{ Levantamentos pedológicos do IAC (escala $1: 100.000)$, kappa $=21.65 \%$ e Acurácia global $=42.05 \%$. } \\
\hline Acurácia $(\%)$ & 61.06 & 22.53 & 77.41 & 8.84 & 35.55 & \\
\hline $\mathrm{L}$ & 8939 & 1668 & 403 & 1083 & 144 & 73.05 \\
\hline $\mathrm{N}$ & 336 & 389 & 37 & 98 & 56 & 42.47 \\
\hline $\mathrm{P}+\mathrm{M}$ & 5345 & 552 & 3904 & 2725 & 1785 & 27.28 \\
\hline $\mathrm{RF}+\mathrm{G}+\mathrm{T}+\mathrm{S}$ & 243 & 29 & 298 & 510 & 12 & 46.70 \\
\hline $\mathrm{RL}+\mathrm{C}+\mathrm{RR}+\mathrm{RQ}$ & 2053 & 321 & 2920 & 1325 & 1813 & 21.50 \\
\hline Acurácia (\%) & 52.84 & 13.15 & 51.63 & 8.88 & 47.59 & \\
\hline
\end{tabular}

L: Latossolos; M; Chernossolos; N:Nitossolos; P:Argissolos; RR:Neossolos Litólicos; RF: Neossolos Flúvicos; C: Cambissolos; S:Planossolos; T:Luvissolos; G: Gleissolos; S: Planossolos; RQ: Neossolos Quartzarênicos.

Na comparação até o segundo nível categórico com o mapa na escala de 1:20.000 a acurácia global foi de $41.47 \%$, com kappa de $25.14 \%$ (Tabela 6). LV e LVA apresentaram os 
maiores números de acertos (acurácia entre 49 e 80\%), com as associações apresentaram os menores números de acertos, por apresentarem muita confusão com as classes de solos PBAC e PVA+M.

Em relação ao mapa na escala de 1:100.000, o kappa foi de $13.17 \%$ e a acurácia global de $25.55 \%$. Observa-se muita confusão entres as classes LV e LVA dos dois mapas, provavelmente devido as diferenças nos critérios para determinação do segundo nível de acordo com o sistema de cores.

A maior correspondência entre o mapa pedológico digital com o mapa na escala 1:20.000, indica um maior nível de detalhe das informações de solo obtidas, e que o mapa de 1:100.000 é mais generalista que o mapa digital obtido. Isso se apresenta com um fato indicativo positivo a metodologia elaborada.

As misturas entre as classes de solos observadas, que levaram a classificação final qualidade regular, como observado pela estatística kappa, pode ser justificada pela própria ocorrência de associações frequentes nos mapas de referência, o que evidencia heterogeneidade pedogenética da região. Isso pode ocorrer pelo fato do relevo da região ser em sua maioria no máximo ondulado, o que faz com que outros fatores de formação do solo tenham mais importância do que apenas a dinâmica da água, regulada pelo relevo.

Outra questão importante é a propagação dos erros de predição, principalmente para os atributos químicos, que tem sido uma problemática observada em vários trabalhos de predição de atributos dos solos via imagens orbitais.

Vários são os trabalhos realizados no mapeamento digita de solos, com variados resultados, podendo citar trabalhos como o de Figueiredo et al.(2008) utilizando regressões logísticas múltiplas a partir de atributos do relevo, obteve kappa de 38\% e acurácia global 62\%, para uma região de 72.000 ha; em uma área de 12.000 ha, Arruda et al.( 2016), obteve kappa de 78\%, a partir de redes neurais via atributos de relevo; Teske et al., (2015), via relevo por árvore de classificação, obtiveram kappa de 46\% para uma área de 90.000 ha; Adhikari et al. (2014) obteve $76 \%$ de acurácia global no mapeamento de solos via relevo na dinamarca.em mais de 4 milhões de ha; Dias et al. (2015), via relevo por arvores de decisão obtiveram kappa 46\%, para uma área de 1.894 ha; Giasson et al. (2013) obteve kappa de 39\% em mapeamento via relevo por árvore de decisão, em área equivalente a 53.000 ha; Demattê et al. (2004), conseguiram mais de $90 \%$ acertos totais na classificação de solos via separação por agrupamentos de espectros, em uma área de 1300; e Demattê et al. (2016), obtiveram kappa de 52 e $42 \%$, com acurácia global de $62 \%$, para uma área de 473 ha. 
Observa-se que para os trabalhos citados o tamanho das áreas mapeadas, por técnicas de mapeamento digital de solos, pode influenciar na concordância desses mapas com existentes de referência. Isso, provavelmente ocorre, porque áreas maiores tendem a apresentar maior complexidade de solos que pode levar o mapa de referência a não discriminar classes de solos existentes na região mapeada, o mapa digital também pode não identificar essas áreas, situação que pode levar a valores menores de kappa na validação dos mapas digitais.

Tabela 6. Matriz de erro para comparação das classificações até $2^{\mathrm{a}}$ ordem entre o mapa digital de solos e levantamentos pedológicos semidetalhados.

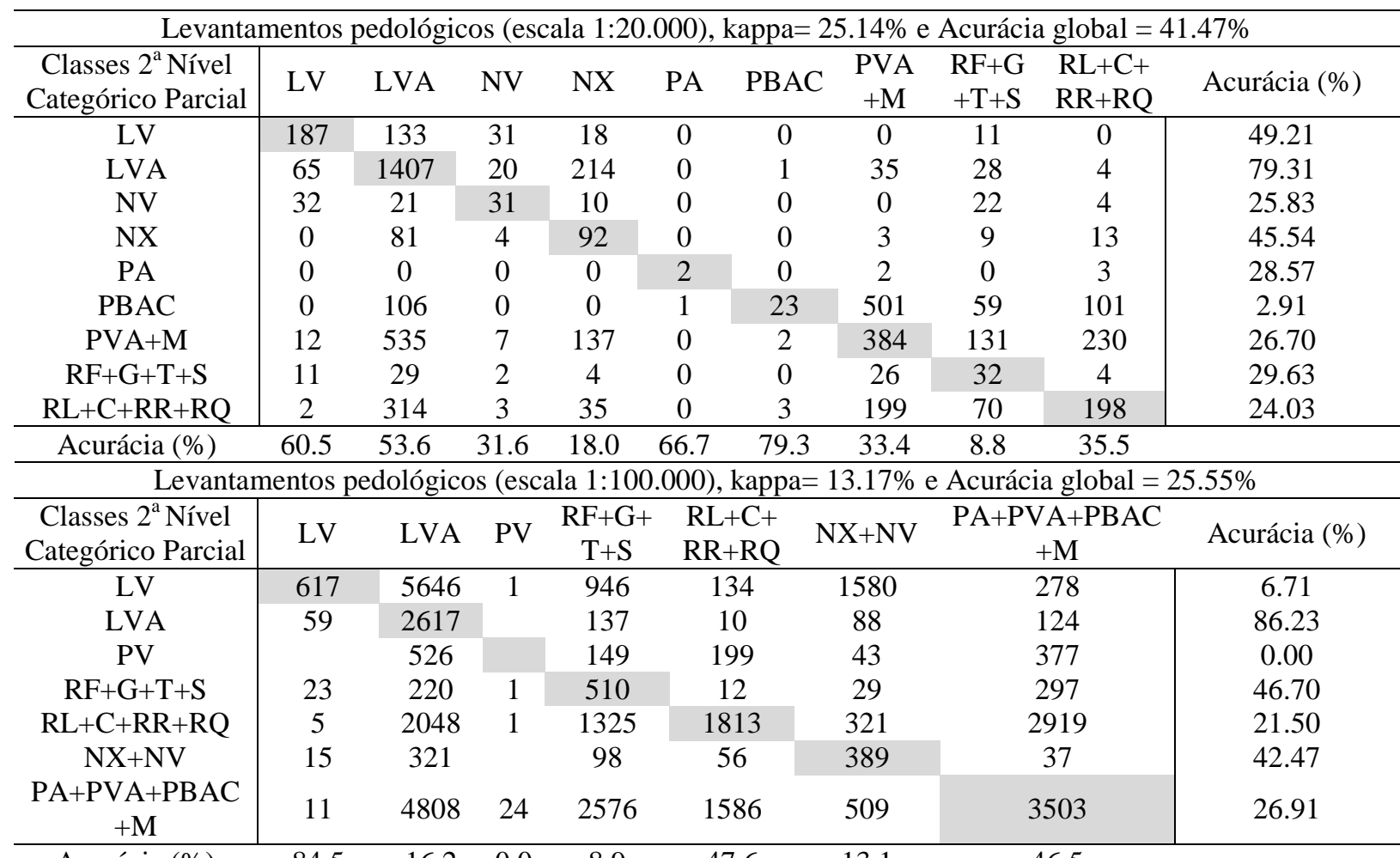

$\begin{array}{llllllll}\text { Acurácia (\%) } & 84.5 & 16.2 & 0.0 & 8.9 & 47.6 & 13.1 & 46.5\end{array}$

LV: Latossolos Vermelhos; LVA: Latossolos Vermelho Amarelos; M; Chernossolos; NV:Nitossolos Vermelhos; NX:Nitossolos Háplicos; PA:Argissolos Amarelos; PAC:Argissolos Acinzentados; PBAC: Argissolos Bruno Acinzentados; PV: Argissolos Vermelhos; PVA: Argissolos Vermelho Amarelos; RR:Neossolos Litólicos; RF: Neossolos Flúvicos; C: Cambissolos; S:Planossolos; T:Luvissolos; G: Gleissolos; S: Planossolos; RQ: Neossolos Quartzarênicos.

Filho et al. (2013) constatou essa complexidade de solos, em estudo próximo a região do presente trabalho. Compararam 4 levantamentos pedológicos detalhados elaborados por método convencional em uma área, e por 4 diferentes experientes pedólogos, e constataram concordância média nesses levantamentos de 62.44\%. Ainda, no mesmo trabalho, compararam um mapa pedológico digital com os mapas tradicionais, e obtveram concordância de $65.22 \%$. Na mesma região, Vasques et al. (2015), obteve acurácia global entre 44 e $52 \%$. Isso mostra a complexidade da região pode ter influnciado tanto o mapa 
digital do presente trabalho, quanto os mapas de referencia, o que pode justificar essa estatistica regular segundo o indice kappa.

Pode-se considerar também, que os resultados estatisticos obtidos nos trabalhos de mapeamento pedológicos citados, não apresentaram valores de kappa e acurácia global muito maiores do que os observados pelo presente trabalho, o evidencia o potencial preditivo da estratégia adotada.

O mapeamento via lógica boolena tem margem potencial para aperfeiçoamento, seja pela melhora das predições dos atributos de entrada, seja pelos critérios elaborados na chave lógistica. Outro fator importante é que cada região pode apresentar características intrínsecas, o que leva a necessidade de ajustes, principalmente no que concerne o relevo e complexidade geológica. Que neste caso especifico, se mostra complexa pelos variados materiais de origem no solo da região, já observados na figura 1 . 


\section{CONCLUSÕES}

1. Os espectros de reflectância de subsuperfície via sensor de laboratório por pontos amostrais, apresentam alta correlação com espectros de reflectância da superfície do solo via sensor de satélite, o que permitiu a espacialização dos espectros de subsuperfície das bandas TM1, TM2, TM3, TM4, TM5 e TM7 Landsat simuladas;

2. $\mathrm{O}$ atributo de subsuperfície argila, apresentam bom resultado preditivo $\left(\mathrm{R}^{2}=0.63\right)$ a partir de espectros de superfície via sensor de satélite;

3. Os atributos argila, matiz, valor e croma, apresentaram os melhores resultados de predição $\left(\mathrm{R}^{2}>0.6\right)$;

4. A cor do solo segundo o sistema munsell apresenta boa correlação com os espectros de reflectância estimados em subsuperfície, o que permite a geração de mapas de cores em subsuperfície.

5. O método multivariado para predição de atributos do solo GWR mostra-se superior na maioria das predições em relação ao método MRL, sendo apenas ligeiramente inferior na predição dos atributos de cor valor e croma, o que coloca esse método com potencial nas estimativas de atributos dos solos;

6. A geração do mapa digital de solos via lógica booleana mostra-se satisfatória, dado a complexidade da distribuição dos solos da região, inclusive observada no mapa de solo de alta intensidade utilizado como referencia comparativa;

7. O método de classificação de solos via lógica booleana apresenta-se com potencial preditivo das classes de solos, com margens para melhorias (acurácia global de 42.05 e $54.46 \%$ na comparação com levantamentos semi-detalhados de baixa e alta intensidade, respectivamente), a medida que atributos dos solos tenham predições melhoradas. 


\section{REFERÊNCIAS}

Adhikari K, Minasny B, Greve MB, Greve MH. Constructing a soil class map of Denmark based on the FAO legend using digital techniques. Geoderma. The Authors; 2014;214215:101-113.

Araújo SR, Söderström M, Eriksson J, Isendahl C, Stenborg P, Demattê JM. Determining soil properties in Amazonian Dark Earths by reflectance spectroscopy. Geoderma. 2015;237238:308-317.

Araújo SR, Wetterlind J, Demattê J a. M, Stenberg B. Improving the prediction performance of a large tropical vis-NIR spectroscopic soil library from Brazil by clustering into smaller subsets or use of data mining calibration techniques. Eur J Soil Sci. 2014;65:718-729.

Arruda GP de, Demattê JAM, Chagas C da S. Mapeamento Digital De Solos Por Redes Neurais Artificiais com Base na Relação Solo-Paisagem. Rev Bras Cienc do Solo. 2013;327338.

Arruda GP de, Demattê JAM, Chagas C da S, Fiorio PR, Souza AB e, Fongaro CT. Digital soil mapping using reference area and artificial neural networks. Sci Agric. 2016;73:266-273. Ben-dor E, Heller D, Chudnovsky A. A Novel Method of Classifying Soil Profi les in the Field using Optical Means. Soil Sci Soc Am J. 2008;72:1113-1123.

Ben-Dor E, Taylor RG, Hill J, Demattê J a M, Whiting ML, Chabrillat S, Sommer S. Imaging Spectrometry for Soil Applications. Adv Agron. 2008;97:321-392.

Bhering SB, Chagas S, Junior WDC. Mapeamento digital de areia , argila e carbono orgânico por modelos Random Forest sob diferentes resoluções espaciais. Pesqui Agropecu Bras. 2016;51:1359-1370.

Camargo OA, Moniz AC, Jorge JA, Valadares J. Métodos de análise química, mineralógica e física de solos do IAC. IAC. Campinas; 1986.

Cambardella CA, Moorman TB, Parkin TB, Karlen DL, Novak JM, Turco RF, Konopka AE. Field scale variability of soil properties in Central Iowa soils. Soil Sci Soc Am J. 1994;58:1501-1511.

Da Rocha MM, Lourenço DA, Leite CBB. Aplicação de krigagem com correção do efeito de suavização em dados de potenciometria da cidade de Pereira Barreto - SP. Geol USP - Ser Cient. 2007;7:37-48.

Dalmolin RSD, Klamt E, Pedron FDA, Azevedo AC De. Relação entre as características e o uso das informações de levantamentos de solos de diferentes escalas. Ciência Rural. 2004;34:1479-1486. 
Dematte J a. M, Fiorio PR, Ben-Dor E. Estimation of Soil Properties by Orbital and Laboratory Reflectance Means and its Relation with Soil Classification. Open Remote Sens J. 2009;2:12-23.

Demattê JAM, Genu AM, Fiorio PR, Ortiz JL, Mazza JA, Leonardo HCL. Comparação entre mapas de solos obtidos por sensoriamento remoto espectral e pelo método convencional. Pesqui Agropecu Bras. 2004;39:1219-1229.

Demattê J, Ramirez-Lopez L, Rizzo R, Nanni M, Fiorio P, Fongaro C, Medeiros Neto L, Safanelli J, da S. Barros P. Remote Sensing from Ground to Space Platforms Associated with Terrain Attributes as a Hybrid Strategy on the Development of a Pedological Map. Remote Sens. 2016;8:826.

DEMATTÊ JLI, DEMATTÊ JAM. Ambientes de produção como estratégia de manejo na cultura da cana-de-açúca. Informações agrônomicas. 2009;127:10-18.

Dias LM da S, Coelho RM, Oliveira SR de M, Barros FMM de. MAPEAMENTO PEDOLÓGICO DIGITAL COM BASE NO RELEVO E TREINAMENTO POR AMOSTRAGEM DE SOLOS DESENVOLVIDOS DE ARENITOS. Rev Equador. 2015;4:36-44.

EMBRAPA Solos. Sistema Brasileiro de Classificação de Solos. 2014.

Environmental Agency. Use of SAGA GIS for spatial interpolation Drought Management Centre for South East Europe. 2010. p. 2-5.

Escadafal R, Girard M-C, Courault D. Munsell soil color and soil reflectance in the visible spectral bands of Landsat MSS and TM data. Remote Sens Environ. Elsevier; 1989;27:37-46. Figueiredo SR, Giasson E, Tornquist GC, Nascimento PC do. Uso de regressões logísticas múltiplas para mapeamento digital de solos no Planalto Médio do RS. Rev Bras Ciência do Solo. 2008;32:2779-2785.

Filho OB, Rizzo R, Lepsch IF, Prado H, Gomes FH, Mazza JA, Demattê JA, Melo. Comparison Between Detailed Digital and Conventional Soil Maps of an Area With Complex. Rev Bras Ciência do Solo. 2013;37:1136-1148.

Fiorio PR, Demattê JAM. Orbital and Laboratory Spectral Data To Optimize Soil Analysis. Sci Agric. 2009;66:250-257.

Fiorio PR, Demattê JAM, Nanni MR, Genú AM. Regressões lineares múltiplas utilizando-se dados espectrais obtidos por sensores em laboratório e orbital, na estimativa de atributos do solo. Simpósio Bras Sensoriamento Remoto. INPE Belo Horizonte; 2003;11:85-92.

Fiorio PR, Demattê JAM, Nanni MR, Genu AM, Martins JA. In situ separation of soil types along transects employing Vis-NIR sensors: a new view of soil evaluation. Rev Cienc Agron. 
2014;45:433-442.

Fongaro CT. Mapeamento granulométrico do solo via imagens de satélite e atributos de relevo. Escola Superior de Agricultura "Luiz de Queiroz; 2015.

Fotheringham AS, Charlton ME, Brunsdon C, Planning C, Fotheringham AS, Charlton ME, Brunsdon C. Geographically weighted regression: a natural evolution of the expansion method for spatial data analysis. Environ Plan A. 1998;30:1905-1927.

Franceschini MHD, Demattê J a. M, da Silva Terra F, Vicente LE, Bartholomeus H, de Souza Filho CR. Prediction of soil properties using imaging spectroscopy: Considering fractional vegetation cover to improve accuracy. Int J Appl Earth Obs Geoinf. 2015;38:358-370.

Gallo BC. Imagens multitemporais do Landsat TM como estratégia no apoio ao levantamento pedológico. Escola Superior de Agricultura “Luiz de Queiroz; 2015.

Genú AM, Demattê J a M. Espectrorradiometria de solos e comparação com sensores orbitais. Bragantia. 2012;71:82-89.

Genú AM, Roberts D, Demattê JAM. The use of multiple endmember spectral mixture analysis (MESMA) for the mapping of soil attributes using Aster imagery. Acta Sci Agron. 2013;35:377-386.

Gerighausen H, Menz G, Kaufmann H. Spatially Explicit Estimation of Clay and Organic Carbon Content in Agricultural Soils Using Multi-Annual Imaging Spectroscopy Data. Appl Environ Soil Sci. 2012;2012:1-23.

Giasson E, Hartemink AE, Tornquist CG, Teske R, Bagatini T. Avaliação de cinco algoritmos de árvores de decisão e três tipos de modelos digitais de elevação para mapeamento digital de solos a nível semidetalhado na Bacia do Lageado. Cienc Rural. 2013;43:1967-1973.

Grunwald S. Current state of digital soil mapping and what is next. Digit Soil Mapp. Springer; 2010. p. 3-12.

He Y. Prediction of soil content using near-infrared spectroscopy. SPIE Newsroom. 2006;810.

Junior JG de AS, Demattê JAM, Genú AM. Comportamento espectral dos solos na paisagem a partir de dados coletados por sensores terrestre e orbital. Rev Bras Cienc do Solo. $2008 ; 727-738$.

Khayamim F, Wetterlind J, Khademi H, Robertson J, Faz Cano A, Stenberg B. Using visible and near infrared spectroscopy to estimate carbonates and gypsum in soils in arid and subhumid regions of Isfahan, Iran. J Near Infrared Spectrosc. 2015;23:155.

Lacerda M, Demattê J, Sato M, Fongaro C, Gallo B, Souza A. Tropical Texture Determination by Proximal Sensing Using a Regional Spectral Library and Its Relationship 
with Soil Classification. Remote Sens. 2016;8:701.

Landis JR, Koch GG. The measurement of observer agreement for categorical data. Biometrics. 1977;33:159-174.

Mathieu R, Pouget M, Cervelle B, Escadafal R. Relationships between satellite-based radiometric indices simulated using laboratory reflectance data and typic soil color of an arid environment. Remote Sens Environ. Elsevier; 1998;66:17-28.

Mendonça-Santos ML, Santos HG. The State of the Art of Brazilian Soil Mapping and Prospects for Digital Soil Mapping. Digit Soil Mapp An Introd Perspect. 2007;31:39-54.

MEZZALIRA S. Folha Geológia de Piracicaba: SF 23-M 300. Inst Geográfico e Geológico do Estado São Paulo. São Paulo; 1966;

Minasny B, McBratney A. Why you don't need to use RPD. Pedometron. 2013;33:14-15.

Moore ID, Gessler PE, Nielsen GA, Peterson GA. Soil attribute prediction using terrain analysis. Soil Sci Soc Am J. Soil Science Society of America; 1993;57:443-452.

Moreira FDS. MOREIRA, FR da S. Uso e avaliação de técnicas de integração e análise espacial de dados em pesquisa mineral aplicadas ao Planalto de Poços de Caldas. INPEInstituto Pesqui Espac. 2001;164.

Mulder VL, de Bruin S, Schaepman ME, Mayr TR. The use of remote sensing in soil and terrain mapping - A review. Geoderma. Elsevier B.V.; 2011;162:1-19.

Nanni MR, Demattê JAM. Spectral Reflectance Methodology in Comparison to Traditional Soil Analysis. Soil Sci Soc Am J. 2006;70:393.

Nanni MR, Demattê JAM, Silva Jr. CA, Romagnoli F, Silva AA, Cezar E. Soil Mapping by Laboratory and Orbital Spectral Sensing Compared with a Traditional Method in a Detailed Level. J Agron. 2014;3:100-109.

Neumann MRB. Mapeamento digital de solos, no Distrito Federal. tese (Doutorado em Geociências) Univ Brasília. 2012;110.

Nocita M, Stevens A, van Wesemael B, Aitkenhead M, Bachmann M, Barthès B, Ben Dor E, Brown DJ, Clairotte M, Csorba A, Dardenne P, Demattê JAM, Genot V, Guerrero C, Knadel M, Montanarella L, Noon C, Ramirez-Lopez L, Robertson J, Sakai H, Soriano-Disla JM, Shepherd KD, Stenberg B, Towett EK, Vargas R, Wetterlind J. Soil Spectroscopy: An Alternative to Wet Chemistry for Soil Monitoring. 2015;139-159.

Odeh IOA, Mcbratney AB, Chittleborough DJ. Spatial prediction of soil properties from landform attributes derived from a digital elevation model. Geoderma. 2006;63:197-214.

Oliveira JB, Prado H. Levantamento pedológico semidetalhado do Estado de São Paulo: Quadrícula de Piracicaba. Campinas, IAC. 1989. 
Post DF, Lucas WM, White SA, Ehasz MJ, Batchily AK, Horvath EH. Relations between soil color and Landsat reflectance on semiarid rangelands. Soil Sci Soc Am J. Soil Science Society of America; 1994;58:1809-1816.

Raij B V., Andrade JCH, Cantarella Quaggio JA. Análise química para avaliação de solos tropicais. IAC. Campinas; 2001.

Rossel RAV. Robust modelling of soil diffuse reflectance spectra by "bagging-partial least squares regression”. J Near Infrared Spectrosc. 2007;15:39-47.

Rossel RAV. ParLeS: Software for chemometric analysis of spectroscopic data. Chemom Intell Lab Syst. 2008;90:72-83.

Rossel RAV, Rizzo R, Demattê J a. M, Behrens T. Spatial Modeling of a Soil Fertility Index using Visible-Near-Infrared Spectra and Terrain Attributes. Soil Sci Soc Am J. 2010;74:1293. Santos HD, HOCHMÜLLER D, Cavalcanti AC, Rego RS, Ker JC, Panoso LA, AMARAL JD. Procedimentos normativos de levantamentos pedológicos. Embrapa-CNPS. 1995. p. 101. Shabou M, Mougenot B, Chabaane Z, Walter C, Boulet G, Aissa N, Zribi M. Soil Clay Content Mapping Using a Time Series of Landsat TM Data in Semi-Arid Lands. Remote Sens. 2015;7:6059-6078.

Shepherd KD, Walsh MG. Development of Reflectance Spectral Libraries for Characterization of Soil Properties. Soil Sci Soc Am J. 2002;66:988.

Soriano-Disla JM, Janik LJ, Viscarra Rossel R a, Macdonald LM, McLaughlin MJ. The Performance of Visible, Near-, and Mid-Infrared Reflectance Spectroscopy for Prediction of Soil Physical, Chemical, and Biological Properties. Appl Spectrosc Rev. 2014;49:139-186.

Steinberg A, Chabrillat S, Stevens A, Segl K, Foerster S. Prediction of Common Surface Soil Properties Based on Vis-NIR Airborne and Simulated EnMAP Imaging Spectroscopy Data: Prediction Accuracy and Influence of Spatial Resolution. Remote Sens. 2016;8:613.

ten Caten A, Dalmolin RSD, Pedron FDA, Ruiz LFC, Silva CA da. An Appropriate Data Set Size for Digital Soil Mapping in Erechim, Rio Grande do Sul, Brazil. Rev Bras Ciência do Solo. 2013;37:359-366.

ten Caten A, Dalmolin RSD, Ruiz LFC, Sebem E, Pereira RS. Pedometria aplicada à predição de classes de solos utilizando de regressões logísticas múltiplas. An. XIV Simpósio Bras. Sensoriamento Remoto. 2009. p. 7685-7692.

Terra FS, Demattê JAM, Rossel RAV. Spectral libraries for quantitative analyses of tropical Brazilian soils: Comparing vis-NIR and mid-IR reflectance data. Geoderma. Elsevier B.V.; 2015;255-256:81-93.

Teske R, Giasson E, Bagatini T. Comparação de esquemas de amostragem para treinamento 
de modelos preditores no mapeamento digital de classes de solos. Rev Bras Cienc do Solo. 2015;39:14-20.

Tropsha A, Gramatica P, Gombar VK. The importance of being earnest: Validation is the absolute essential for successful application and interpretation of QSPR models. Qsar Comb Sci. 2003;22:69-77.

Vasques GM, Demattê J a. M, Rossel RAV, Ramírez López L, Terra FS, Rizzo R, De Souza Filho CR. Integrating geospatial and multi-depth laboratory spectral data for mapping soil classes in a geologically complex area in southeastern Brazil. Eur J Soil Sci. 2015;n/a-n/a.

Zeng R, Zhang G-L, Li D-C, Rossiter DG, Zhao Y-G. How well can VNIR spectroscopy distinguish soil classes? Biosyst Eng. Elsevier; 2016;

Ziadat FM. Land suitability classification using different sources of information: Soil maps and predicted soil attributes in Jordan. Geoderma. 2007;140:73-80. 
ANEXOS 


\section{ANEXO A. Resultados do pós processamento das imagens de solo exposto.}

\section{Grade amostral utilizada}

A análise geoestatística partiu de uma grade amostral 200 × 200 m dos dados de reflectância de cada uma das bandas TM do MSE, onde foram escolhidos os valores dos parâmetros de ajuste, efeito pepita, patamar e alcance dos modelos de semivariogramas teóricos, aos semivariogramas empíricos.

O tamanho da grade amostral utilizada deveu-se ao espaçamento mínimo permitido pela capacidade de processamento do software utilizado. Após escolha dos parâmetros de ajuste, realizou-se a krigagem ordinária para cada uma das bandas TM do MSE representadas na grade amostral, gerando-se assim, uma superfície de informação espectral cobrindo $100 \%$ do quadrante da área de estudo, aqui denominado de Mosaico de Solo Exposto Krigado (MSEKG).

Após a krigagem, realizou-se uma validação da krigagem a partir de uma grade amostral de 100x100 m com os valores de reflectância extraídos do MSE, para esta etapa o software utilizado permitiu o processamento em uma grade amostral mais adensada.

O processamento geoestatístico foi realizado no pacote Spatial and Geostatistics do Software SAGA GIS versão 2.1.2 associado ao software Microsoft Excel segundo Environmental Agency (2010).

\section{Mosaico de solo exposto}

A Figura 11a apresenta uma composição colorida RGB 543 em zoom de aproximação, sobre o mosaico de solo exposto pré e pós-processamento, antes da etapa de krigagem. Observa-se a eliminação de pequenos ruídos, o recobrimento de pequenas lacunas, e uma transição visualmente mais suave dos valores de reflectância percebidos na composição colorida citada. Essa transição mais suave indica que as variabilidades de reflectância entre os períodos das imagens que compõem o mosaico final ficaram menos perceptíveis, devido ao pós-processamento inicial.

A Figura 11b, apresenta o mosaico de solo exposto (MSE) do pós-processamento inicial, o mosaico de solo exposto Krigado (MSEKG) e o MSE unido ao MSEKG, formando um mosaico totalmente preenchido e aqui recebendo a identificação pela sigla MSEKGU. Assim, uma área que era coberta por $67 \%$ de informação espectral de solo exposto, passa a ser 
de $100 \%$, o que permite o mapeamento via espectros de áreas agrícolas que anteriormente não apresentavam as informações de reflectância em solo exposto.

(a)
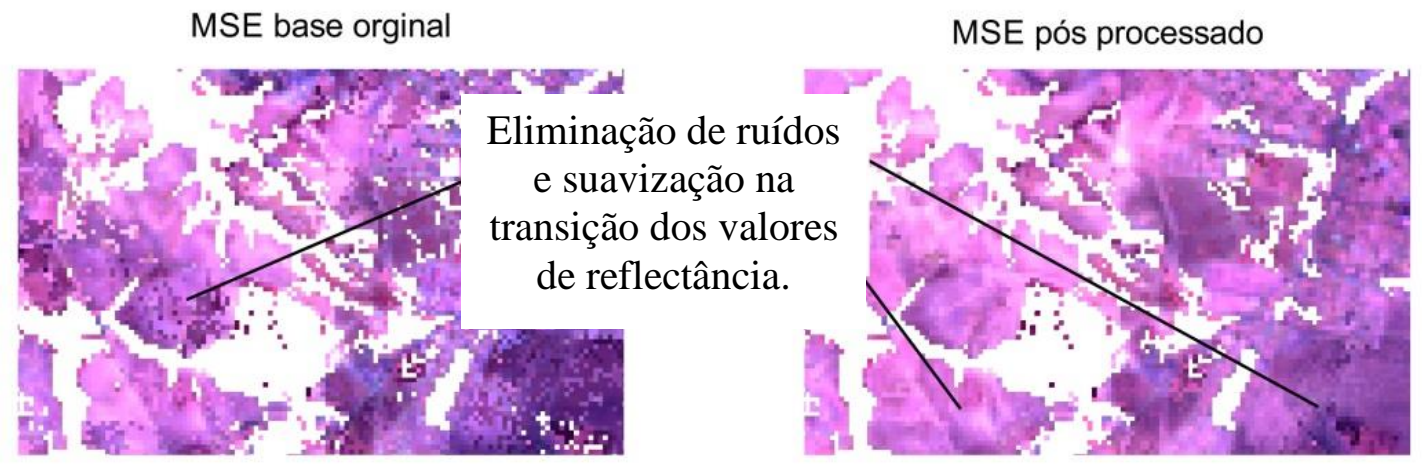

(b)
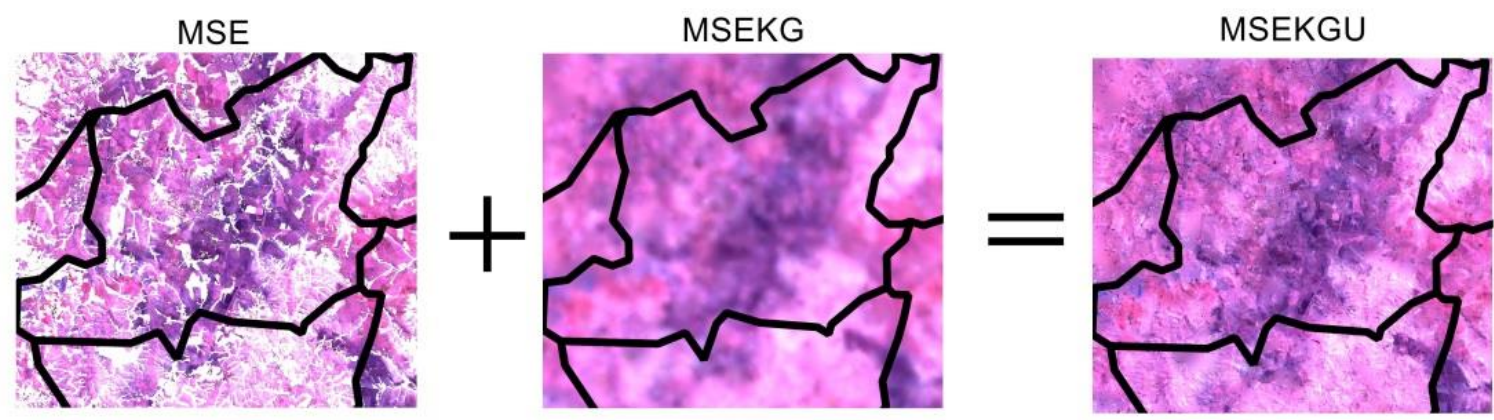

Figura 11. a. Zoom sobre o mosaico de solo exposto da base original e após processamento da mesa; b. Mosaico de solo exposto (MSE) pós processamento, Mosaico de solo exposto krigado (MSEKG) e a união do MSE com o MSEKG formando o MSEKGU.

A análise geoestatística para fins de krigagem e geração do mosaico de solo exposto MSEKG, com metodologia já apresentada na Figura 2, demonstra que os valores de reflectância da imagem de solo exposto, apresentaram forte dependência espacial, que segundo Cambardella et al. (1994) é avaliada pelo grau de dependência espacial dos atributos em estudo. Estes são classificados com dependência espacial forte, quando o efeito pepita é menor ou igual a $25 \%$ do patamar, moderada quando está entre 25 e $75 \%$ e fraca quando for maior que 75\%. Essa informação é apresentada na Tabela 7, juntamente com os valores de ajuste do modelo teórico exponencial aos semivariogramas empíricos, da distribuição espacial dos valores de reflectância de cada uma das bandas do mosaico de solo exposto, apresentados na Figura 12. Na referida tabela, observa-se um grau de dependência espacial entre 13 e $21 \%$, o que como já discutido, encontram-se num grau forte de dependência espacial. Essa forte dependência espacial observada, demonstra o potencial de espacialização de valores de reflectância pelo método de interpolação por krigagem, gerando informações que podem ser usadas em outros estudos.

A validação do MSEKG gerado pela interpolação por krigagem ordinária apresentou resultados satisfatórios, com $\mathrm{R}^{2} \geq 0.6$ e RPIQ próximos ou maiores que 2 para todas as bandas 
TM, o que indica boa predição dessas informações (Tabela 8). Isto demonstra que a interpolação/predição de valores de reflectância pelo método krigagem, apresenta-se com bom potencial na geração de superfícies de informações espectrais que podem ser utilizadas nos mais diversos estudos.

Tabela 7. Parâmetros do semivariograma para as bandas TM Landsat-5 do mosaico de solo exposto

\begin{tabular}{llllll}
\hline Variável $^{1}$ & Modelo & Efeito Pepita $\left(\mathrm{C}_{0}\right)$ & Patamar ( C ) & Alcance (a) & GD (\%) \\
\hline TM 1 & Exponencial & 2.0 & 9.5 & 5300 & 21.1 \\
TM 2 & Exponencial & 1.5 & 9.7 & 5000 & 15.5 \\
TM 3 & Exponencial & 2.4 & 12.4 & 5100 & 19.4 \\
TM 4 & Exponencial & 4.5 & 27.5 & 5500 & 16.4 \\
TM 5 & Exponencial & 14.0 & 74.0 & 7000 & 18.9 \\
TM 7 & Exponencial & 5.2 & 39.7 & 6100 & 13.0 \\
\hline 1TM1(450-520 nm); TM2 & $(520-600 \mathrm{~nm}) ;$ TM3 $(630-690 \mathrm{~nm}) ;$ TM4 (760-900 nm); TM5 (1550-1750 \\
nm); TM7(2080-2350 nm) & & &
\end{tabular}

A Figura 12 apresenta os semivariogramas das bandas do mosaico de solo exposto e suas respectivas linhas de ajuste do modelo exponencial. Na referida figura, observa-se que valores mais próximos entre si são mais semelhantes (efeito pepita), e à medida que se distanciam vãos ficando menos semelhantes até uma distância (alcance) onde a variância não mais aumenta (patamar), com a estabilização da curva. Essa variação dos dados entre o efeito pepita e o patamar até o alcance, mostra a dependência espacial dos dados analisados, indicando que os dados de refletância podem ser estimados via krigagem. O alcance observado, mostra que é possível especializar valores de reflectância de solos a partir de grade amostral maiores do que a grade amostral utilizada para a análise geoestatística dos presentes dados.

Tabela 8. Validação da espacialização dos espectros das bandas TM landsat-5 pelo método de krigagem ordinária

\begin{tabular}{ccccc}
\hline Banda TM Landsat 5 & Número de amostras predição/validação & $\mathrm{R}^{\mathbf{2}}$ & RMSE & RPIQ \\
\hline TM1 & & 0.60 & 1.72 & 4.95 \\
TM2 & $0071 / 32390$ & 0.67 & 1.62 & 5.47 \\
TM3 & 0.62 & 1.96 & 1.92 \\
TM4 & 0.67 & 2.75 & 2.13 \\
TM5 & 0.64 & 4.52 & 2.17 \\
TM7 & 0.71 & 3.14 & 2.36 \\
\hline
\end{tabular}

${ }^{\mathrm{I}}$ TM1(450-520 nm); TM2 (520-600 nm); TM3 (630-690 nm); TM4 (760-900 nm); TM5 (1550-1750 nm); TM7(2080-2350 $\mathrm{nm})$ 

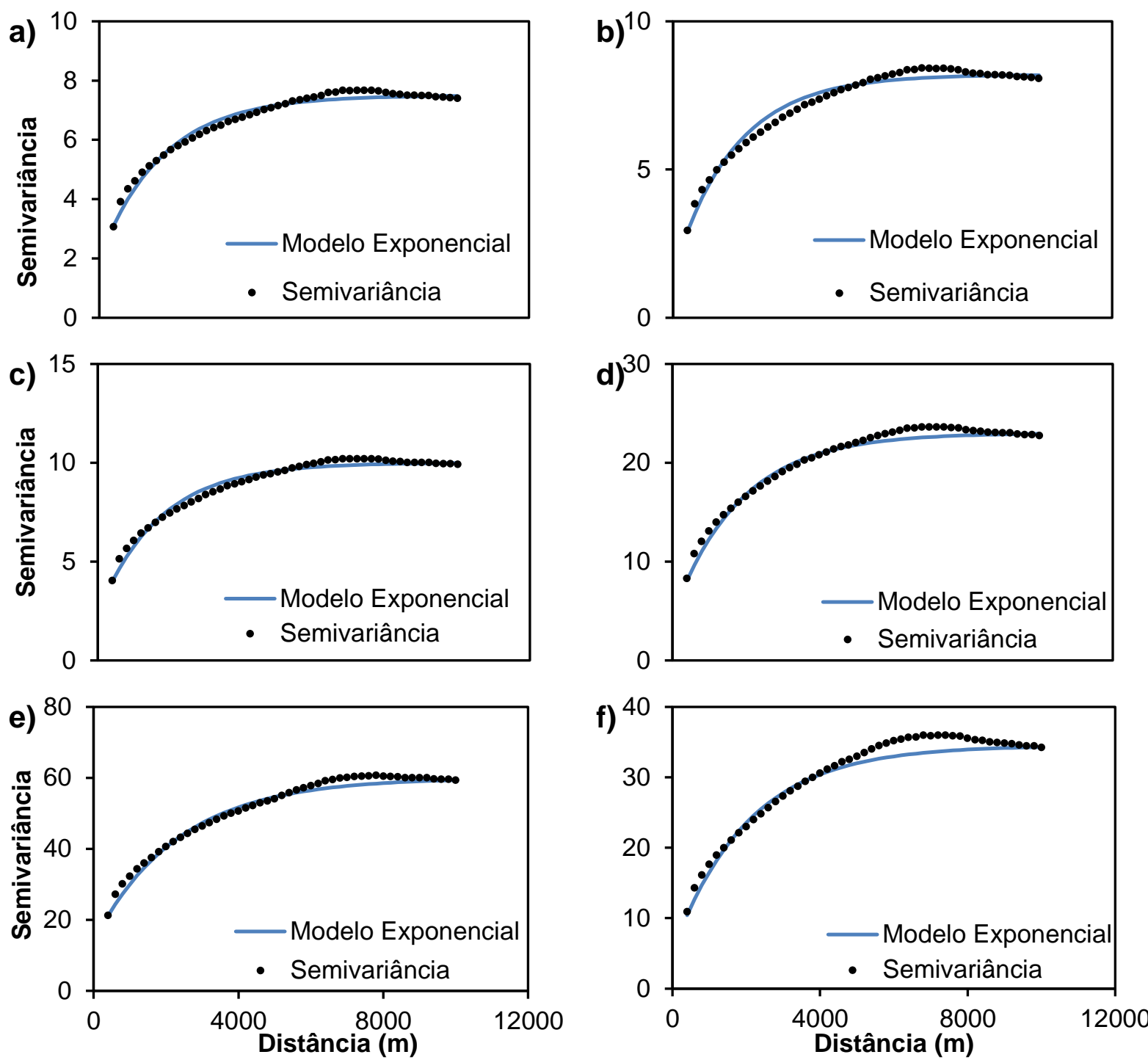

Figura 12. Semivariogramas das bandas da imagem de solo exposto: a.TM1(450-520 nm); b.TM2 (520-600 nm); c.TM3 (630-690 nm); d.TM4 (760-900 nm); e.TM5 (1550-1750 nm);f.TM7(2080-2350 nm)

\section{CONCLUSÕES}

1. O pós processamento da imagem de solo exposto aplicado neste trabalho aumenta a área de solo exposto e suaviza as transições de reflectância originadas das variações intertemporais das imagens;

2. Os espectros de reflectância das imagens de satélite apresentam forte dependência espacial, segundo análise geoestatística, o que demonstra o potencial de predição da reflectância coletada não apenas de sensores orbitais mas também de pontos amostrais via sensores de laboratório. 


\section{ANEXO B. Classes de solos observadas no Mapa Digital de Solos}

Tabela 9. Resumo das classes de solos encontradas no mapa digital de solos.

\begin{tabular}{|c|c|c|}
\hline Classes de solos & Área (ha) & $\%$ \\
\hline LATOSSOLOS VERMELHO AMARELOS distróficos argilosos & 14972.83 & 31.27 \\
\hline NEOSSOLOS FLÚVICOS + GLEISSOLOS distróficos argilosos & 4364.77 & 9.12 \\
\hline ARGISSOLOS VERMELHO AMARELOS distróficos argilosos & 3945.65 & 8.24 \\
\hline NEOSSOLOS LITÓLICOS + CAMBISSOLOS distróficos argilosos & 2831.66 & 5.91 \\
\hline NITOSSOLOS HÁPLICOS distróficos argilosos & 2459.93 & 5.14 \\
\hline ARGISSOLOS VERMELHO AMARELOS distróficos médio argilosos & 2354.80 & 4.92 \\
\hline LATOSSOLOS VERMELHO AMARELOS distróficos médio argilosos & 2323.70 & 4.85 \\
\hline LATOSSOLOS VERMELHO AMARELOS distroférricos argilosos & 1753.58 & 3.66 \\
\hline NEOSSOLOS FLÚVICOS + GLEISSOLOS distróficos médio argilosos & 1471.55 & 3.07 \\
\hline ARGISSOLOS VERMELHO AMARELOS distróficos médio arenosos & 1225.73 & 2.56 \\
\hline LATOSSOLOS VERMELHO AMARELOS eutróficos argilosos & 833.92 & 1.74 \\
\hline ARGISSOLOS VERMELHO AMARELOS abrupticos distróficos médio arenosos & 793.82 & 1.66 \\
\hline NEOSSOLOS FLÚVICOS + GLEISSOLOS distróficos médio arenosos & 698.29 & 1.46 \\
\hline NEOSSOLOS FLÚVICOS + GLEISSOLOS eutróficos argilosos & 681.68 & 1.42 \\
\hline NEOSSOLOS REGOLÍTICOS distróficos médio arenosos & 659.97 & 1.38 \\
\hline LATOSSOLOS VERMELHOS distróficos argilosos & 604.61 & 1.26 \\
\hline LATOSSOLOS VERMELHO AMARELOS distrófico médio arenosos & 559.51 & 1.17 \\
\hline ARGISSOLOS VERMELHO AMARELOS abrupticos distróficos médio argilosos & 558.19 & 1.17 \\
\hline NITOSSOLOS HÁPLICOS distroférricos argilosos & 546.85 & 1.14 \\
\hline NEOSSOLOS REGOLÍTICOS distróficos médio argilosos & 510.75 & 1.07 \\
\hline NITOSSOLOS HÁPLICOS eutróficos argilosos & 348.81 & 0.73 \\
\hline NEOSSOLOS REGOLÍTICOS distróficos argilosos & 341.04 & 0.71 \\
\hline NITOSSOLOS VERMELHOS distróficos argilosos & 313.64 & 0.66 \\
\hline ARGISSOLOS VERMELHO AMARELOS abrupticos distróficos argilosos & 238.15 & 0.50 \\
\hline NEOSSOLOS LITÓLICOS + CAMBISSOLOS eutróficos argilosos & 235.78 & 0.49 \\
\hline NEOSSOLOS QUATZARÊNICOS distróficos arenosos & 217.81 & 0.45 \\
\hline LATOSSOLOS VERMELHOS eutróficos argilosos & 188.65 & 0.39 \\
\hline NEOSSOLOS LITÓLICOS + CAMBISSOLOS distroférricos argilosos & 177.85 & 0.37 \\
\hline ARGISSOLOS VERMELHO AMARELOS distroférricos argilosos & 167.33 & 0.35 \\
\hline NITOSSOLOS VERMELHOS distroférricos argilosos & 166.61 & 0.35 \\
\hline LUVISSOLOS argilosos & 107.42 & 0.22 \\
\hline Outro solos & 1226.84 & 2.56 \\
\hline Total & 47881.73 & 100.00 \\
\hline
\end{tabular}

